\title{
Role of oxygen on Nuclear factor erythroid-2-like 1 (NFE2L1 or Nrf1) \\ function and stability in HEK293T cells
}

\author{
By
}

Haiyun Bo

B.Sc., Carleton University, 2015

\begin{abstract}
A thesis submitted to the Faculty of Graduate Studies and Research in partial fulfillment of the requirements for the degree of

Masters of Science in Biology
\end{abstract}

\author{
Carleton University \\ Ottawa, Ontario, Canada
}

April 2019

C2019, Haiyun Bo 


\section{ACKNOWLEDGEMENTS}

I would like to thank my supervisor, Dr. William G. Willmore for providing me with constant support, guidance, trust, encouragement and countless learning opportunities throughout the completion of my thesis. I would like to thank Dr. Kyle Biggar for helping me with peptide synthesis. I would like to thank Dr. Sue Twine and Kelly Fulton from NRC for running analysis on my samples. I would like to express my gratitude to the professors on my committee, Dr. John Vierula and Dr. Matthew Pamenter for their advice and support during my thesis. I would like to thank Anand Chopra for always providing helpful suggestions to my study. I would like to thank the members of Dr. Willmore's lab, especially Shana Cameron and Rowida Mohamed for always being there for me. I would also like to thank all members from Dr. Ashkan's lab for being supportive and great study companions. Finally, I would thank my family, especially my mom and dad for their endless and loving support. I would also like to thank my husband for his love and support throughout my study. 


\section{ABSTRACT}

Oxidative stress has been recognized as one of the key players involved in human aging and progression of many chronic diseases, including cancer. Cells undergo oxidative stress when the overproduction of reactive oxygen species (ROS) within the cell outweighs its antioxidant defenses. As a defence mechanism, a series cytoprotective genes are initiated and regulated by various transcription factors in order to minimize oxidative damage to the cell. Nuclear factor erythroid-2-like 1 (Nrfl) is a transcription factor found to be one of the vital regulators of antioxidant and detoxification genes through the antioxidant response element (ARE). However, as a primarily endoplasmic reticulum (ER) membrane bound transcription factor, the mechanism of how Nrf1 is being processed, translocated from ER to nucleus, post-translational modified and degraded are still unclear. This study aimed to determine Nrf1 is modified, in an oxygen-dependent manner, by hydroxylation and this regulates the protein function. A potential hydroxylation site was identified on Nrfl that may be target for modification by the Hypoxia-Inducible Factor Prolyl Hydroxylase 2 (PHD2). Oxygen-dependent hydroxylation of Nrf1 may affect it function under low oxygen (hypoxic $\left(\begin{array}{ll}1 \% & \mathrm{O}_{2}\end{array}\right)$ ) conditions when hydroxylation is absent. The potential hydroxylation site was mutated in Nrfl and wildtype and mutant proteins were overexpressed in human embryonic kidney (HEK293T) cells. We found that the activity of Nrf1, under hypoxic conditions, is at least 1.5-fold higher than it is under normoxic conditions $\left(21 \% \mathrm{O}_{2}\right)$ from reporter assays and that this increase was highest when the PHD2 was co-expressed with wildtype Nrf1. Similarly, our Western blot analysis showed an elevated level of Nrf1 under hypoxic conditions and this was enhanced with co-expression of PHD2. We hypothesized that Nrf1 is hydroxylated by PHD2 hydroxylases in an oxygen-dependent manner and this affects Nrf1 function and protein stability. Enhancement of Nrf1 function under hypoxic conditions will be further investigated as a 
potential target for therapeutic peptides that will reduce its hydroxylation and augment its antioxidant and detoxification activities. 


\section{Contents}

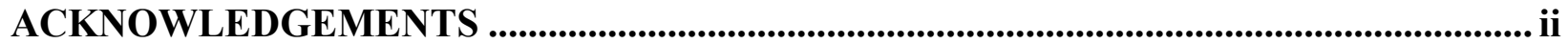

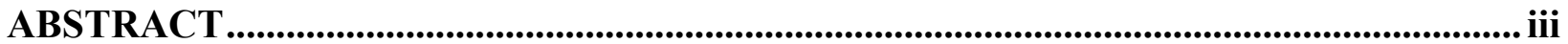

LIST OF FIGURES ................................................................................................................ vii

LIST OF TABLES ...................................................................................................................... ix

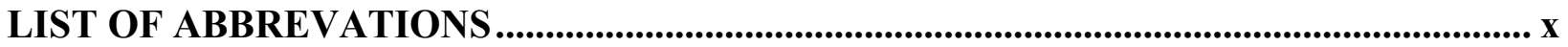

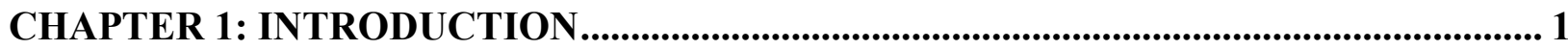

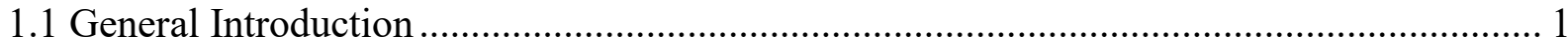

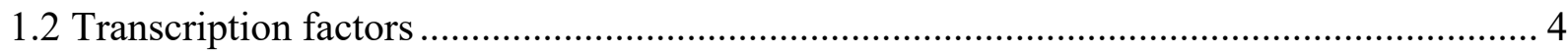

1.3 The hypoxia-inducible factor 1 (HIF-1) and its regulation by prolyl hydroxylase 2 (PHD2)

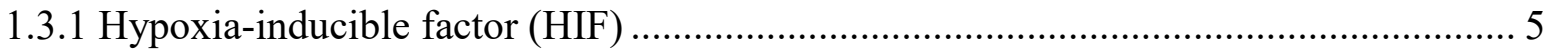

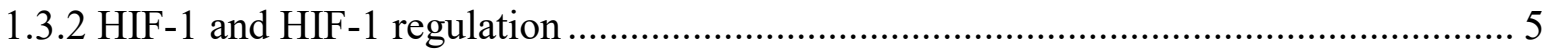

1.4 Nuclear factor-erythoid 2 (NF-E2) p45-related factor-1 (Nrf1) and nuclear factor-erythoid

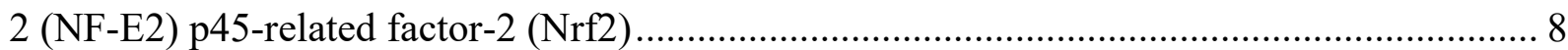

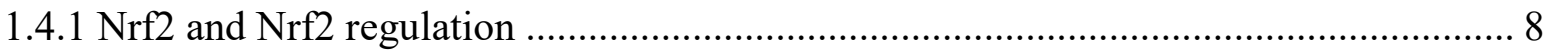

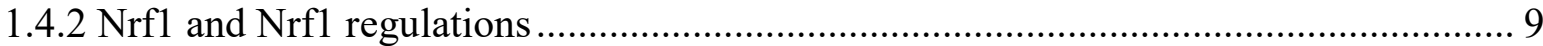

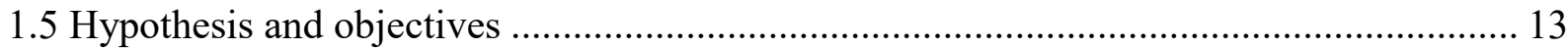

CHAPTER 2 MATERIALS AND METHODS.............................................................. 28

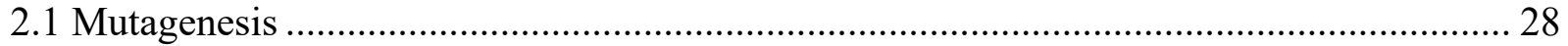

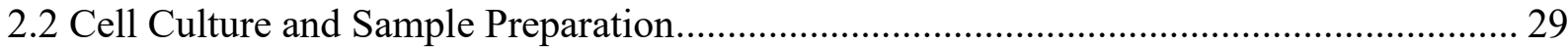

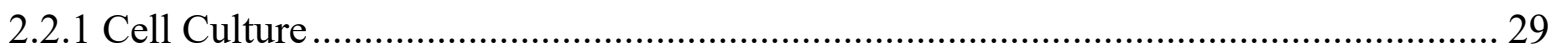

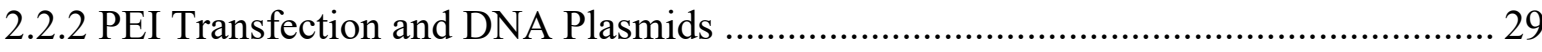

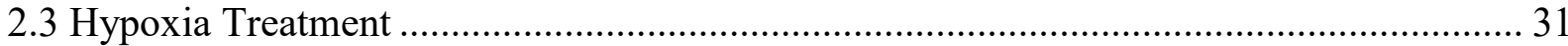

2.4 Cell Harvest, Whole-Cell Lysis and Sample Preparation..................................................... 31

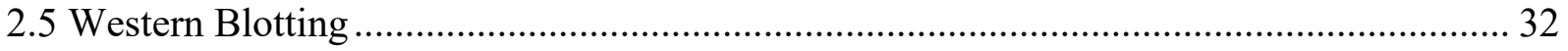

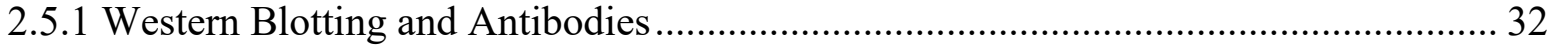

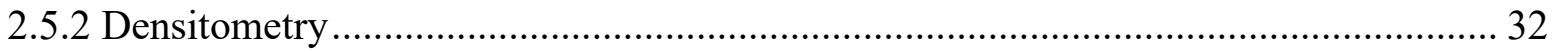

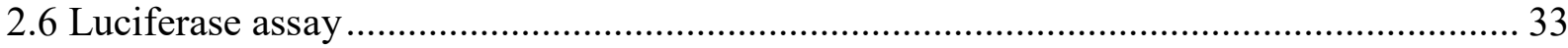

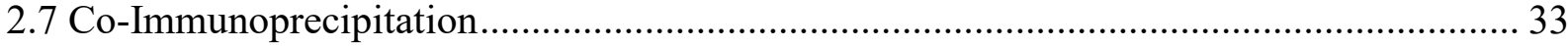

2.7.1 DSP (dithiobis[succinimidylpropionate]) Crosslinker Treatment ................................ 33 
2.7.2 Co-Immunoprecipitation..................................................................................... 34

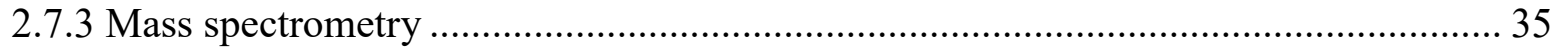

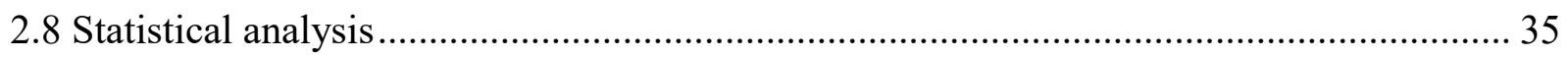

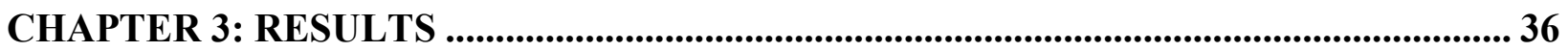

3.1 Effects of Hypoxia On NFE2L1 (Nrf1) Protein Expression................................................ 36

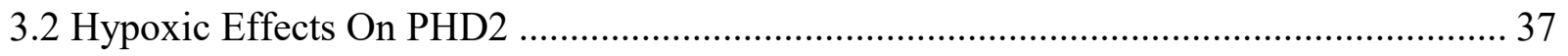

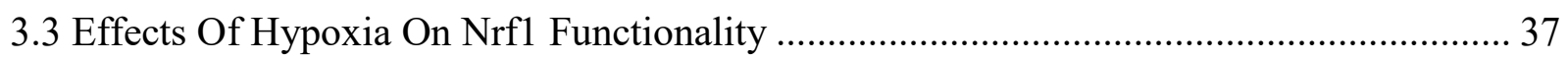

3.4 Nrf1 Co-Immunoprecipitation and Mass Spectrometry ................................................... 38

CHAPTER 4: DISCUSSION AND CONCLUSION ..........................................................55

4.1 Oxygen has an effect on Nrf1 expression and PHD2 hydroxylation may not directly lead to

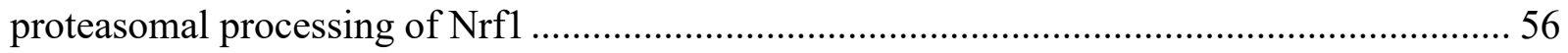

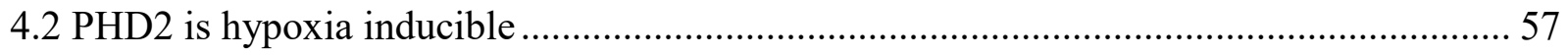

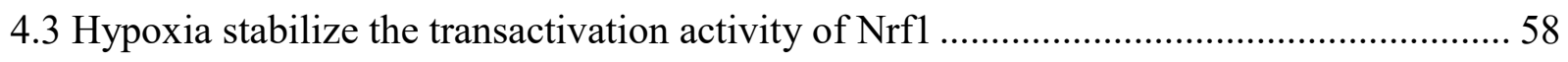

4.4 Hydroxylation through PHD2 may be transient and is indirectly involved in ubiquitination

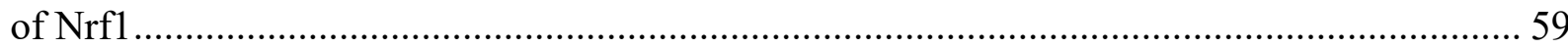

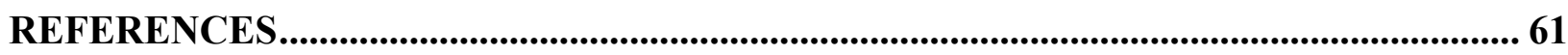

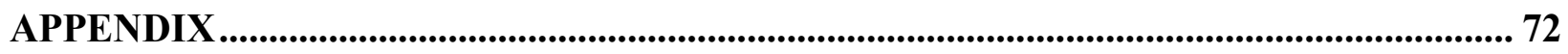




\section{LIST OF FIGURES}

Figure 1: Mitochondria ROS regulation in endothelial cells................................................... 15

Figure 2: Endogenous and exogenous source that contribute to reactive oxygen species (ROS) production and the main enzymatic and non-enzymatic proteins involved in antioxidant defence mechanism. 18

Figure 3: Oxygen- and iron-dependent regulation of HIF transcription factors. 20

Figure 4: The cap'n'collar family of transcription factors and their common structural domains.

Figure 5: The multiple forms and cleaved products of Nrf1.

Figure 6: Proposed mechanisms by which Nrfl activates ARE/EpRE-responsive gene expression.

Figure 7: Western blot analysis of endogenous Nrf1 protein expression profile in response to various durations of low oxygen (1\%) treatment. 40

Figure 8: Western blot analysis of Nrf1 protein expression in response to various durations of low oxygen (1\%) treatment in transient transfected HEK293T cells.

Figure 9: Western blot analysis of Nrf1 protein expression in response to 24 hours of low oxygen (1\%) treatment in comparison to normoxia in transient transfected HEK293T cells. 44

Figure 10: Western blot analysis of endogenous PHD2 protein expression profile in response to various durations of low oxygen $(1 \%)$ treatment 46

Figure 11: Western blot analysis of PHD2 protein expression in response to various duration of low oxygen (1\%) treatment in transient transfected HEK293T cells. 48

Figure 12: Western blot analysis of PHD2 protein expression in response to 24 hours of low oxygen (1\%) treatment in comparison to normoxia in transient transfected HEK293T cells. ..... 50 
Figure 13: Luciferase reporter assay analysis of Nrf1 transactivation activity in response to 24

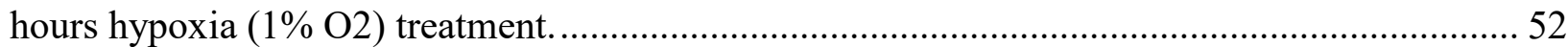




\section{LIST OF TABLES}

Table 1: Protein functional domains of humanNFE2L1 (Nrf1). Amino acid residues are numbered according to the full length (p120) protein.

Table 2: Mass spectrometry analysis for protein samples (endogenous, wtNrf1, mutNrf1, wtNrf1/PHD2

or mutNrf1/PHD2 overexpressed) post co-immunoprecipitation using anti-Nrf1 antibody..... 


\section{LIST OF ABBREVATIONS}

$\mathrm{AD}$ : acidic domain

ARE: Antioxidant Response Element

ATP: adenosine triphosphate

bZIP: basic leucine zipper

bHLH: basic helix-loop-helix

CAT: catalase

CNC: Cap'n'collar

CTD: C-terminal domain

DDI2: DNA-damage inducible 1 homolog 2

DTT: dithiothreitol

EPO: erythropoietin

ER: endoplasmic reticulum

ETC: electron transport chain

FBXW7: F-box/WD repeat-containing protein 7

FIH-1: factor inhibiting HIF-1

HEK293T: Human Embryonic Kidney cells

HIF: Hypoxia-Inducible Factor

HRE: Hypoxia Response Element 
Hrd1: ERAD-associated E3 ubiquitin-protein ligase HRD1

Keap1: Kelch-like ECH-associating protein 1

KO: knockout

Mt: Metallothionein

NehL: Nrf2-ECH homology like

NF-E2: nuclear factor-erythroid 2

NHB: N-terminal homology box

Nqo1: NAD(P)H: quinone oxidoreductase 1

NST: Asn/Ser/Thr-rich

NTD: N-terminal domain

ODDD: oxygen dependent degradation domain

2-OG: 2-oxoglutarate

PHD: prolyl hydroxylase

PNGase: peptide:N-glycosidase

Praja-1: E3 ubiquitin-protein ligase Praja-1

pVHL: von Hippel-Lindau tumor suppressor protein

RNS: Reactive Nitrogen Species

ROS: Reactive Oxygen Species 
SCF: Skp1-Cul1-F-box protein

Skn-1: Skinhead 1

SOD: superoxide dismutase

TMc/TMi/TMp: C-terminal/intermediate/semihydrophobic transmembrane 


\section{CHAPTER 1: INTRODUCTION}

\subsection{General Introduction}

Living organisms are subjected to continuous fluctuations of external environment and they resist and manage these external stressors by making biological defence adjustments in order to keep internal fluctuations within a narrow range. In doing so, they avoid damage to their internal systems (Buchman, 2002). Environmental changes can be beneficial as they may force the organisms to eliminate less favored traits and promote traits that help them become more adaptable to the current environment. Depending on the type and duration of the stress, cells initiate protective responses (e.g. antioxidant, detoxification and cytoprotective defence mechanisms) or destructive stress responses (e.g. apoptosis, autophagocytosis and necrosis) (Simone et al., 2009). As the stress builds up and outweighs the defence capacity, the impaired stress response system can lead to the development of tissue inflammation, aging, chronic/metabolic/neurodegenerative diseases, and cancer (Richard, 2008).

Although stress promotes metabolic adaptation, many types of stresses have been identified that cause damage to macromolecule integrity, including environmental pollutants, ionizing radiation (Kempner, 1993), heavy metals (Farrer and Pecoraro, 2002), reactive oxygen species (ROS) (Kasprzak, 2002), and hypoxia (Ella et al., 1999; Amber and Michelle, 2007; Annalisa, 2015). One common characteristic among these different stresses is that they all lead to the production of highly reactive ROS and reactive nitrogen species (RNS). ROS and RNS are unstable small molecules containing unpaired electrons which actively seek out other electrons to pair with in order to lower their reactivity and become stabilized. Typically, hydroxyl radical $(\bullet \mathrm{OH})$, superoxide $\left(\mathrm{O}_{2} \bullet^{-}\right)$, and hydrogen peroxide $\left(\mathrm{H}_{2} \mathrm{O}_{2}\right)$ are main biological ROS species, and nitric oxide (NO•) and peroxynitrite $\left(\mathrm{ONOO}^{-}\right)$are two main biological RNS 
species (Rafael, 2013). Among these, the hydroxyl radical is the most reactive and has the shortest half life, whereas hydrogen peroxide is relatively more stable and membrane permeable, which leads to prolonged and broader damages to the cells. As a result, DNA, proteins and lipids become more susceptible to structural damage when cells are stressed and ROS (or RNS) production outweighs antioxidant capacity. Common deleterious modifications are a) single pyrimidine and purine base lesions, b) intra-strand cross-links and DNA-protein adducts in DNA molecules, c) amino acid oxidation in proteins and d) lipid peroxidation. ROS and RNS are not only generated from exogenous sources, they are also constantly produced as by-products from various metabolic pathways (e.g. the electron transport chain (ETC), ATP production, inflammatory responses) and enzymatic activities (e.g. xanthine oxidase, lipoxygenase, and the NADPH oxidase) within the cell (Kanti and Syed, 2010; Guzik and Harrison, 2006). For instance, aerobic organisms rely on reduction of $\mathrm{O}_{2}$ via mitochondrial oxidative phosphorylation to generate energy (ATP), but paradoxically the process also contributes to ROS production when $\mathrm{O}_{2}$ is partially reduced and free electron leakage occurs [Figure 1] (Droge, 2002). Therefore, cells exposed to oxygen environments are constantly combating oxidative stress and they have developed a series of antioxidant defence mechanisms in order to restore redox balance, as well as resetting critical homeostatic variables. Cells rely on signaling proteins to sense changes in regulated variables to ensure timely response to cellular stress via transcriptional induction, post-translational modifications, protein-protein/DNA interactions and downstream regulation of stress response genes (Raj and Raslan, 2014). For example, oxygen-responsive hypoxia-inducible factor $1 \alpha$ (HIF-1 $\alpha$ ) detects depletion in intracellular oxygen levels; it forms heterodimer with HIF- $\beta$ and bind to hypoxia response elements (HREs) in order to further regulates hypoxic-responsive target genes 
(Weidemann and Johnson, 2008). ROS and RNS induce protein misfolding, which leads to endoplasmic reticulum (ER) stress. ER stress sensing and signaling is effected by three ER transmembrane transducers: inositol-requiring kinase 1 (IRE1), pancreatic ER elF2a kinase (PERK), and activating transcription factor 6 (ATF6) (Cao and Kaufman, 2012). Following the initial signaling events, cells initiate either elimination or adaptive responses, which are usually associated with alterations in protein stability and functionality, as well as DNA processing. Specifically, cells have two major strategies to counteract oxidative stress, recruitment of endogenous antioxidant enzymes and transcriptional activation of antioxidant defence system (Reddy, 2008). Many of these antioxidant enzymes are involved in direct contact with ROS/RNS (intermediary metabolites) by catalyzing the production of less reactive species (e.g. $\mathrm{H}_{2} \mathrm{O}, \mathrm{O}_{2}$, and $\mathrm{H}_{2} \mathrm{O}_{2}$ ), such as superoxide dismutases (SODs), catalase (CAT), glutathione peroxidases (GPXs) and peroxiredoxins (PRDXs) [Figure 2]. Some other antioxidant enzymes, such as glutathione reductase (GR), NAD(P)H:quinone oxidoreductase 1 (NQO1), thioredoxin reductase (TXNRD), and glutathione-S-transferases (GSTs) are generally involved in thiol recycling and secondary reactive metabolites (e.g. aldehyde and peroxide) excretion via reduction or conjugation reactions. Thiol-containing compounds such as glutathione (GSH (reduced) and GSSG (oxidized)), thioredoxins (TRX), glutaredoxins (GRX), and peroxiredoxins (PRDX) act as electron acceptors and oxidative stress buffers, which undergo rapid oxidation and regeneration reactions to maintain normal intracellular redox status. Together, endogenous antioxidant enzymes form a strong, first response defence network for cells under oxidative stress. Meanwhile, 84 different antioxidant genes (e.g. Gpx, Prdx, Cat, Gsr, Txnrd, Sod, and Nox) are activated by transcriptional induction, which ensures 
adequate antioxidant enzymes to be functionally active while the cells are under stress (Gornicka et al., 2011).

Although many recent studies have elucidated oxidative stress as the underlying cause to a number of chronic diseases, including steatophepatitis (fatty liver disease), Parkinson's disease, cardiovascular disease, diabetes, and metabolic syndrome (Gornicka et al., 2010; McMurray et al., 1999; VonHarsdorf et al., 1990; Eizirik and Mandrup-Poulsen, 2001; Kharroubi et al., 2004; Droge, 2002) (with a large number of critical antioxidant enzymes being recorded and up-regulated under disease status), an understanding of mechanisms of transcriptional control and regulation of corresponding antioxidant gene expression is still not clear.

\subsection{Transcription factors}

Transcription factors are DNA-binding proteins that regulates gene transcriptions in eukaryotes. They interact with specific DNA sequences located in the promoter region and are closely adjacent to their downstream target genes. Generally, transcription factors are divided into two categories, basal and regulatory transcription factors. Regulatory transcription factors are promotor-specific and they are activated by induction. They are classified in families, according to their DNA-binding domain (Ohtsuji et al., 2008). In addition to DNA binding domains, transcription factors contain other domains that facilitate their transcriptional gene regulation. The activity of transcription factors is closely regulated by mechanisms involving their synthesis, subcellular translocation, post-translational modification, proteolysis, dimerization, and protein-protein interactions with other cofactors (Potters et al. 2010). 


\subsection{The hypoxia-inducible factor 1 (HIF-1) and its regulation by prolyl hydroxylase 2}

\section{(PHD2)}

\subsubsection{Hypoxia-inducible factor (HIF)}

Hypoxia-inducible factors (HIFs) are recognized as a crucial regulatory protein for cellular response to reduced oxygen levels in intracellular environment. HIFs belong to a family of heterodimeric transcription factors and they consist of an $\alpha$-subunit and a $\beta$-subunit. Both subunits have three isoforms each (HIF-1 $\alpha$, HIF-2 $\alpha$, HIF-3 $\alpha$, HIF-1 $\beta$, HIF-2 $\beta$ and HIF$3 \beta$ ). The HIF- $\beta$ subunits are also known as the Aryl hydrocarbon Nuclear Translocator, or ARNT, and can heterodimerize with a number of different transcription factor alpha subunits. The HIF- $\alpha$ subunits are oxygen-sensitive and regulated post-translationally via hydroxylation (Chepelev and Willmore, 2011). They have a common basic helix-loop-helix (bHLH) domain for DNA binding, a Per-Arnt-Sim (PAS) domain to facilitate its heterodimerization and a cterminal transactivation domain (C-TAD) for transactivation activity (Niecknig et al., 2012). HIF binds to a specific DNA sequence (5'-NCGTG-3') within hypoxia response elements (HREs) which modulate target genes responsible for the maximal maintenance of cellular homeostasis and optimal cellular adaptation during hypoxia (Semenza, 2011).

\subsubsection{HIF-1 and HIF-1 regulation}

The involvement of HIF-1 in the cellular response to hypoxia was first described by Dr. Gregg Semenza in 1992. HIF-1 was reported to bind to the sequence to transcriptionally activate the erythropoietin (EPO) gene under hypoxic conditions (Semenza and Wang, 1992). Erythropoietin is a glycoprotein hormone which regulates the maturation of erythrocytes, as a result of hypoxia. Other studies have indicated that hypoxia induces the expression of vascular 
endothelial growth factor (VEGF), which is an important signaling protein for angiogenesis (Ferrara and Davis-Smyth, 1997; Ferrara, 1999). The transcriptional activation of VEGF gene is mediated by the binding of HIF-1 to a cis-acting HRE (Forsythe et al., 1996). The study also showed that VEGF gene is not activated under low oxygen conditions when HIF-1 is knocked out (Forsythe et al., 1996). Both erythropoiesis and angiogenesis are adaptative strategies for maintaining cell viability and homeostasis during low oxygen conditions. However, the transcriptional control by HIF-1 can also lead to negative impacts on cells. HIF-1 is reported to promote glycolysis in cancer cells and repress the fatty acid catabolism leading the proliferation of tumor cells (Vander et al., 2009; Huang et al., 2014).

The $\beta$-subunit of HIF is constitutively expressed in the cell, whereas HIF- $\alpha$ is highly regulated by oxygen. HIF- $\alpha$ has very short half life and is targeted for proteasomal degradation due to its oxygen-liable property when oxygen is adequate. Specifically, under normoxic conditions, proline residues 564 and 402 within the oxygen dependent degradation domain (ODDD) of HIF- $\alpha$ are rapidly targeted for hydroxylation by 2-oxoglutarate (2-OG) dependent dioxygenases, designated prolyl hydroxylase (PHDs) in humans (Masson et al., 2001). These two prolines are both found in a highly conserved sequence, the "LXXLAP" sequence, where $\mathrm{X}$ represents any amino acid, which are specific to substrate proteins of PHDs (Huang et al., 2002). The hydroxylated prolines are marked for the recognition by the von Hippel-Lindau (pVHL) tumor suppressor protein, which then leads to the ubiquitination of HIF- $\alpha$ by E3 ubiquitin ligase, by which HIF-1 $\alpha$ undergoes proteasomal degradation. In contrast, HIF- $\alpha$ is stabilized when hydroxylation is inactivated due to the lack of oxygen and the recognition by $\mathrm{pVHL}$ is not accessible, as a result, HIF- $\alpha$ escapes from degradation and enters nucleus forming HIF- $\alpha / \beta$ heterodimer to proceed gene regulations. In addition to oxygen availability, PHDs 
required $\mathrm{Fe}^{2+}$ as a cofactor, the rate of prolyl hydroxylation can be limited when $\mathrm{Fe}^{2+}$ level is low [Figure 3] (Chepelev and Willmore, 2011).

Recent studies have stated that the c-terminal transactivation domain (C-TAD) is also oxygen regulated. A third hydroxylation is found on the asparagyl residue 803 (Asn 803) located in the c-terminal transactivation domain by an another $\mathrm{Fe}^{2+}$ and 2-oxoglutarate (2-OG) dependent dioxygenases termed factor inhibiting HIF-1 (FIH-1) (Mohan et al., 2001). It is suggested that this post-translational modification has little effect on $\alpha$-subunit stability, instead it inhibits HIF-1 transcriptional activity by altering the accessibility of the coactivator, p300/CBP binding to HIF complex. Specifically, in normoxic conditions, hydroxylation of Asn 803 occurs and introduces steric hinderance, which prevents the interaction of HIF-1 with its coactivator p300/CBP (Lisy and Peet, 2008).

Other post-translational modifications that are not oxygen dependent, such as lysine acetylation (Lys 532) and threonine phosphorylation (Thr 796 and Thr 844 in HIF-1 $\alpha$ and HIF$2 \alpha$ respectively) also have substantial impact on HIF transcriptional activity (Jeong et al., 2002; Gradin et al., 2002). Acetylation is observed to stabilize HIF-1 $\alpha$ and pVHL interaction and when the lysine is mutated to arginine, lack of acetylation enhances the stability of HIF-1 $\alpha$ (Jeong et al., 2002). Phosphorylation of conserved threonines facilitates the binding of HIF-1 $\alpha$ to the $\beta$-subunit, which is another alternative pathway in stabilizing HIF activity.

Through different post-translational modifications and cofactor interactions, HIF-1 activity is tightly regulated, which subsequently controls its target genes. To date, there have been hundred of target genes of HIF-1 identified and these genes broadly span many critical functions in the cell. 


\subsection{Nuclear factor-erythoid 2 (NF-E2) p45-related factor-1 (Nrf1) and nuclear factor- erythoid 2 (NF-E2) p45-related factor-2 (Nrf2)}

The cap'n'collar (CNC) basic-leucine zipper (bZIP) transcription factors is another important family of regulatory proteins that response to various cellular stress including oxidative stress, endoplasmic reticulum stress, and electrophilic xenobiotic stress. This family consists of the Caenorhabditis elegans skinhead-1 (Skn-1) protein (Bowerman et al. 1992; 1993), the Drosophila melanogaster cap'n'collar-isoform C (CncC) protein (Mohler et al. 1991; 1995), and the vertebrate activators nuclear factor erythoid 2 (NF-E2) p45 subunit (Chan et al., 1993b), transcription factor 11 (TCF11) (Johnsen et al., 1996; Kobayashi et al., 1999), locus control region-factor 1 (LCR-F1 or Nrf1ß) (Farmer et al., 1997; Caterina et al., 1994), nuclear factor erythoid 2 like 1 (Nrf1 or NFE2L1) (Andrews et al., 1993; Chan et al. 1993a; 1993b; Zhang et al. 2006; 2007; 2014a), Nrf2 (NFE2L2) (Moi et al., 1994), and Nrf3 (NFE2L3) (Kobayashi et al., 1999; Chénais et al., 2005; Chevillard et al., 2011). BTB and CNC homolog 1 (Bach 1) (Blouin et al., 1998; Ohira et al.,1998) and Bach 2 (Muto et al. 1998; Sasaki et al. 2000) are naturedly truncated isoform of Nrf1 and a caspase-cleaved form of Nrf2 respectively, which missing the transactivation domain, which serve as repressors (Ohtsubo et al., 1999; Dhakshinamoorthy et al., 2005; Wang et al., 2007) [Figure 4].

\subsubsection{Nrf2 and Nrf2 regulation}

Among all the family members, Nrf2 is the most extensively studied and it is known as the master regulator of the antioxidant response. Nrf2 controls the basal and induced expression of an array of antioxidant genes by binding to a specific consensus DNA sequence 5'-TGACNNNGC-3' ( $\mathrm{N}$ is any nucleotide) termed antioxidant response element (ARE), 
along with small Maf proteins. Common antioxidant proteins such as glutathione Stransferase (GST) and NAD(P)H:quinone oxidoreductase 1 (NQO1), sulfiredoxin (SRX1), glutathione peroxidase 2 (GPX2), and enzymes involved in glutathione (GSH) synthesis (e.g. glutamate cysteine ligase (GCL), GSH synthetase (GS)) are mediated and upregulated through active Nrf2 transcriptional machinery upon the exposure to oxidant (McMahon et al., 2001). Additionally, Nrf2 is also known involved in the basal and stress-inducible expression of a number of antioxidants and phase II detoxification (Itoh et al. 1997, McMahon et al. 2001).

Nrf2 is negatively regulated by a Kelch-like ECH-associating protein 1 (Keap1). The cysteine residues, Cys151, Cys273, and Cys288 contained in Keap1 protein serves a important role in stress sensing (Saito et al., 2016). In normal non-stressed cell, cysteine residues in Keap1 are not oxidized by ROS and it remains in its normal conformational state, which enables it to interact with Nrf2. The binding of Keap1 supresses Nrf2 activity and marks Nrf2 for polyubiquitination, leading to its degradation by the proteasome (Kobayashi et al., 2004; Furukawa et al., 2005).

\subsubsection{Nrf1 and Nrf1 regulations}

As one of the main CNC/bZIP transcription factors, Nrf1, is not as well described as Nrf2. Unlike Nrf2, which is primarily located in cytosol, Nrf1 has an N-terminal domain (NTD), which mediates Nrf1 subcellular localization to the endoplasmic reticulum (ER) membrane upon its translation. The transactivation domain (TAD) of Nrfl, located in the ER lumen, is glycosylated resulting in an inactive form of Nrf1 (120kDa). Nrf1 stays inactive until its TAD is retrotranslocated into cytoplasm, where deglycosylation occurs, allowing the partial proteolytic processing by proteasome from the $\mathrm{N}$-terminus, which leads to different truncated 
forms of Nrf1 [Figure 5] (Bugno et al., 2015). These Nrf1 isoforms can enter the nucleus, dimerize with small Maf proteins and binds to AREs to initiate the transcriptional control activities. However, these Nrf1 isoforms are revealed having distinctive and even opposing functions in ARE-dependent gene regulation (Zhang et al., 2007; Wang and Chen, 2006). A truncated version of Nrf1, p65, is reported acting as an inhibitor to all Nrf activities (Wang and Chan, 2006). By using multiple deletion mutants of Nrf1 on NTD, Zhang et al. has shown that the transactivation activity of Nrfl is the highest when NTD is fully omitted (Zhang et al., 2006).

Nrf1 has been shown as an important regulator in many Nrf1 knockout (KO) studies, Chan et al. reported early embryonic death of mice in utero in global Nrf1 knockout (Chan et al., 1998), while Xu et al. found that when Nrf1 is knocked out in the liver, this leads to nonalcoholic steatohepatitis, which later develops into hepatoma (Xu et al., 2005). Other studies have focused on finding out whether Nrf1 and Nrf2 are governing same set of antioxidant/detoxification genes through AREs by disrupting either Nrf1 or Nrf2 activity in mice. Surprisingly, mice with Nrf1 KO and normal Nrf2 do not make to adulthood and die very early on in an embryonic stage, whereas mice with normal Nrf1 and Nrf2 KO have normal development and do not spontaneously develop cancer (Chan et al. 1996). Nrf1 also regulates proteasome gene induction and proteasome functions. After treatment with proteasome inhibitor, mice with wildtype Nrf1 were restored and maintained proteasome homeostasis after 24 hours, whereas Nrf1 KO mice had severe damage in the liver (Lee et al., 2013).

It was suggested that the expression of many ARE-driven genes were decreased when Nrf1 is knocked out in the system, which indicate that Nrf1 and Nrf2 have distinct yet overlapping roles in ARE-dependent gene regulation (Ohtsuji et al., 2008). Similar to Nrf2, 
Nrf1 targets a number of glutathione biosynthetic and antioxidant enzymes, such as glutamatecysteine ligase (GCL), glutathione peroxidase 1 (GPX1), glutathione S-transferase (GST), and catalase (Bugno et al., 2015). Metallothionein-1 (MT-1) and -2 (MT-2) genes are found highly responsive to the removal of Nrf1, the gene expression of MT-1 and MT-2 are significantly decreased by 7.76 -fold and 8.03 -fold respectively and are not affected by Nrf2 activities (Ohtsuji et al., 2008). The study done by Ohtsuji et al. also revealed that, when Nrf1 is knocked out, many ARE-dependent genes that targeted by Nrf2 had experienced an increased fold change ranging from 0.65 to 2.9 -fold (Ohtsuji et al. 2008). Genes that are involved in ERassociated protein degradation (ERAD) and proteasome function are including proteasome subunit alpha (PSMA), proteasome subunit beta (PSMB), nuclear protein localization 4 (NPL4), and ubiquitin fusion degradation 1 (UFD1) (Lee et al., 2013; Lee et al., 2011; Radhakrishnan et al. 2014; Sha and Goldberg, 2014).

The precise regulation of Nrfl expression is still not completely understood and the pathway of truncated Nrf1 produced is still highly controversial. Zhang et al. recently reported that $\mathrm{Nrf1}$ is activated by mTORC1 (mammalian target of rapamycin complex 1), a protein that is primarily involved in sensing cellular nutrient/energy/redox status and controlling protein synthesis (Hay and Sonenberg, 2004; Kim et al., 2002). It was shown that the mTORC1 activated expression of proteasome subunits is dependent upon the Nrf1 transcriptional activity. Nrf1 was initially described as not being regulated by Keap1, but was later found to interact with Keap1 with only 28\% affinity, comparing to that of Nrf2 (Kobayashi and Yamamoto, 2004). However, the role of Keap1 in regulating the activity of Nrf1 is not clear. To date, the activation mechanism for how glycosylated Nrf1 is retro-translocated into cytoplasm and generates active form of Nrf1 still remains to be determined. 
Many antioxidant response genes show changes in expression when oxidative stress is introduced. This becomes more significant when there was an impairment in Nrfl function. Therefore, it is believed that the connection between oxidative stress and Nrf1 is strong. Oxidative stress, caused by ROS, can be led by endogenous and external sources and hypoxia has been recognized as one of the sources, in more recent years. Gregory et al. examined ROS the production of ROS in pulmonary (PASMC) and systemic (SASMC) smooth muscle cells using redox-sensitive, ratiometric fluorescent protein sensor (RoGFP) and their results showed hypoxia increased ROS release from the mitochondria and subsequentially increased ROS concentration in cytosol (Waypa et al., 2010). In 2017, Coimbra-Costa et al. has shown that the acute hypoxia $\left(7 \% \mathrm{O}_{2}\right.$ for 6 hours) introduced to rat had increased the ROS production in the brain tissue. They found the following three ROS markers were significantly elevated; lipid peroxidation, protein oxidation and nitric oxide levels. The following were significantly decreased; SOD, GSH, GPx and the reduced/oxidized glutathione (GSH/GSSG) ratio (Coimbra-Costa et al., 2017). All these changes did not become more significant after the reoxygenation. Proteins are primarily modified by post-translational modifications (PTM) upon the translation in order for orderly control in their stability and functions. It is highly possible that an unknown signalling pathway by PTM was induced by ROS after hypoxia treatment, which led to the upregulation of transcriptional factor activity, such as Nrf1. As a result, its target genes were seen to be upregulated. Oxygen, as the known substrate of PHD2, is involved in the oxidation of proteins, as well as ROS production. We are investigating whether hydroxylation by PHD2 in Nrf1 is a possible PTM signalling pathway that contributes in Nrf1 regulation. 


\subsection{Hypothesis and objectives}

In this study, we aimed to determine that Nrfl is modified, in an oxygen-dependent manner, by hydroxylation and this regulates protein function. It has been shown that posttranslational modifications such as phosphorylation, acetylation, and hydroxylation can play important roles in regulating protein activity. A potential hydroxylation site, proline 398 in Nrfl, was identified to possibly be targeted for modification by the Hypoxia-Inducible Factor Prolyl Hydroxylase 2 (PHD2). Interestingly, this proline is contained in a highly conserved "LXXLAP" sequence; the same sequence which targets HIF- $\alpha$ for oxygen-dependent modification by prolyl hydroxylases. We investigated the hypothesis whether possible oxygendependent hydroxylation of Nrf1 affects its function under low oxygen (hypoxic $\left(1 \% \mathrm{O}_{2}\right)$ ) conditions when hydroxylation is absent, which may also affect the stability of Nrf1.

The potentially hydroxylated proline residue in Nrfl was mutated to Alanine and wildtype and mutant proteins were overexpressed in human embryonic kidney (HEK293T) cells along with the overexpression of PHD2 protein. We introduced hypoxia by treating the cells with low oxygen $\left(1 \% \mathrm{O}_{2}\right)$ and the transcriptional activity of both mutant and wild Nrfl were examined by luciferase reporter assay. The level of Nrf1 expression and stability were accessed using Western blotting. Co-immunoprecipitation was performed, followed up with mass spectrometry to determine whether an interaction between PHD2 and Nrf1 was present.

We found that the activity of Nrf1, under hypoxic conditions, is at least 1.5-fold higher than it is under normoxic conditions $\left(21 \% \mathrm{O}_{2}\right)$ from reporter assays indicating hypoxia activates the transcriptional activity of Nrfl. Our Western blot analysis showed an elevated level of active form of $\mathrm{Nrfl}(95 \mathrm{kDa})$ as the hypoxia treatment prolonged in both transfected and endogenous samples. The results from mass spectrometry revealed a E3 ubiquitin-protein 
ligase Praja 1 that is only found when proline is mutated, which indicates there might be steric hinderance introduced by hydroxylation in wild type Nrf1 that affects the interaction of Nrf1 with this ubiquitin ligase. 


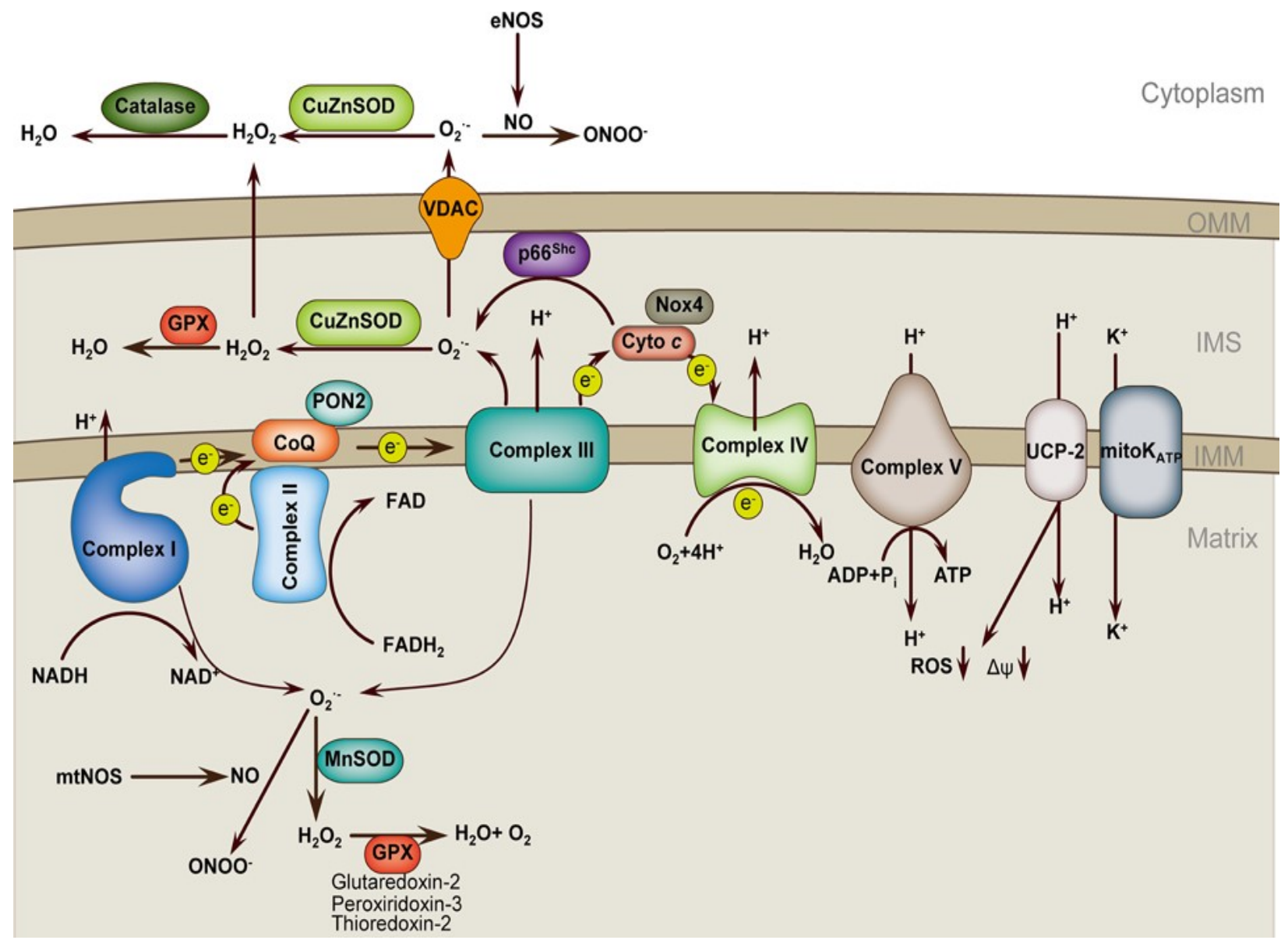

Figure 1: Mitochondria ROS regulation in endothelial cells. 
Respiratory chain complexes I-IV generate the proton gradient over the mitochondrial inner membrane that drives ATP generation by ATP synthase (complex V). Electrons $\left(\mathrm{e}^{-}\right)$from NADH and FADH2 pass through complex I and complex II, respectively, and then to complex III via the co-enzyme ubiquinol (CoQ). Cytochrome $c$ transfers electrons from complex III to complex IV, which reduces $\mathrm{O}_{2}$ to form $\mathrm{H}_{2} \mathrm{O}$. Flow of electrons is accompanied by proton $\left(\mathrm{H}^{+}\right)$ transfer across the inner mitochondrial membrane (IMM) at complexes I, III, and IV, creating an electrochemical gradient, $\Delta \psi_{\mathrm{m}}$. Protons renter the mitochondrial matrix through complex $\mathrm{V}$, which uses the proton-motive force to generate ATP. UCPs and mitoK $\mathrm{K}_{\mathrm{ATP}}$ allow protons to return to the matrix, reducing ROS formation. Complex I leaks electrons to generate $\mathrm{O}_{2}{ }_{2}$ toward the matrix, whereas complex III generates $\mathrm{O}_{2}{ }_{2}$ toward both matrix and intermembrane space (IMS). p66 $6^{\text {Shc }}$ in the IMS subtracts electrons from cytochrome $c$ to produce $\mathrm{O}_{2}^{*}$. Superoxide is dismutated to $\mathrm{H}_{2} \mathrm{O}_{2}$ by CuZnSOD in IMS and by MnSOD in the matrix. $\mathrm{H}_{2} \mathrm{O}_{2}$ is reduced to $\mathrm{H}_{2} \mathrm{O}$ by glutathione peroxidase (GPX) using GSH, and the resultant oxidized glutathione (GSSG) is reduced back to GSH by glutathione reductase. $\mathrm{O}_{2}^{*}$ can interact with $\mathrm{NO}$ to form $\mathrm{ONOO}^{*}$, which may cooperate with $\mathrm{O}_{2}^{*}$ to uncoupling eNOS and amplify ROS production. PON2, Paraoxonase 2; NOX4, nicotinamide adenine dinucleotide phosphate oxidase 4; UCP2, uncoupling protein 2;

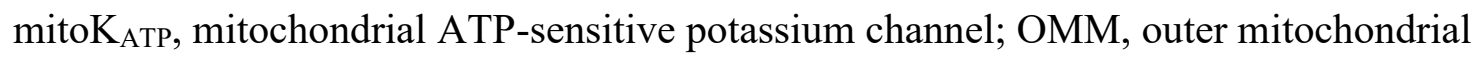
membrane. (Tang et al., 2014) 


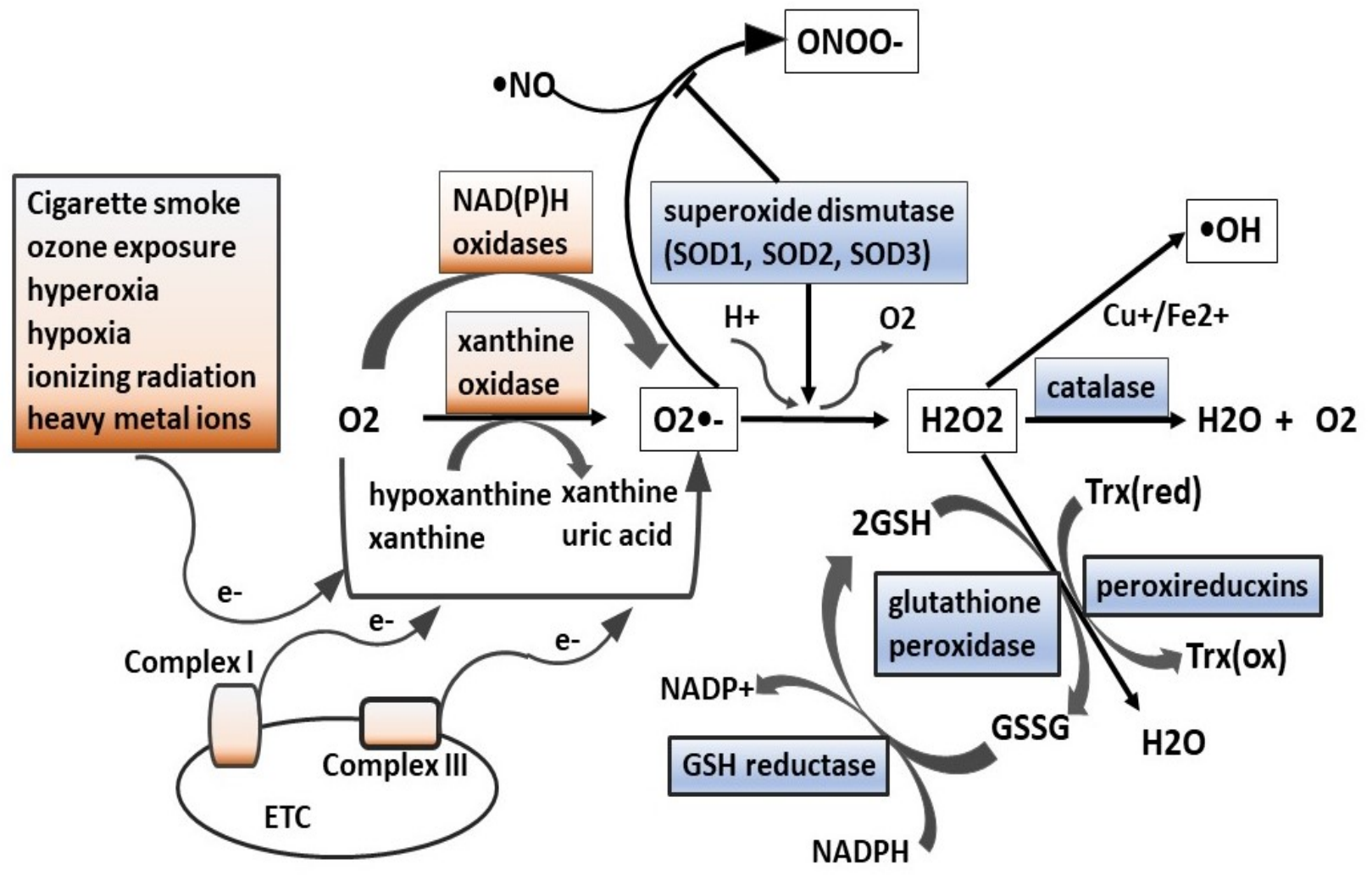


Figure 2: Endogenous and exogenous source that contribute to reactive oxygen species (ROS) production and the main enzymatic and non-enzymatic proteins involved in antioxidant defence mechanism.

Highly reactive free radicals or ROS can be generated upon exposure to cigarette smoke, ozone exposure, hyperoxia, hypoxia, ionizing radiation and heavy metal ions. Metabolic activities, such as oxidative phosphorylation $r$ for ATP production via electron transport chain (ETC), enzymatic activities of $\mathrm{HAD}(\mathrm{P}) \mathrm{H}$ and xanthine oxidase can also generate ROS (superoxide $\mathrm{O}_{2} \bullet^{-}$) as byproduct. Antioxidant enzymes, such as superoxide dismutase (SOD1, SOD2, SOD3), catalase (CAT), glutathione peroxidase (GPXs), and glutathione reductase (GR) are critical converting reactive ROS into more stabilized molecules. Non-enzymatic compounds such as peroxireducxins (PRDXs), thioreducxins (TRXs), glutathione (GSH) and NADPH serve as electron recycler and buffer for cellular redox status. 


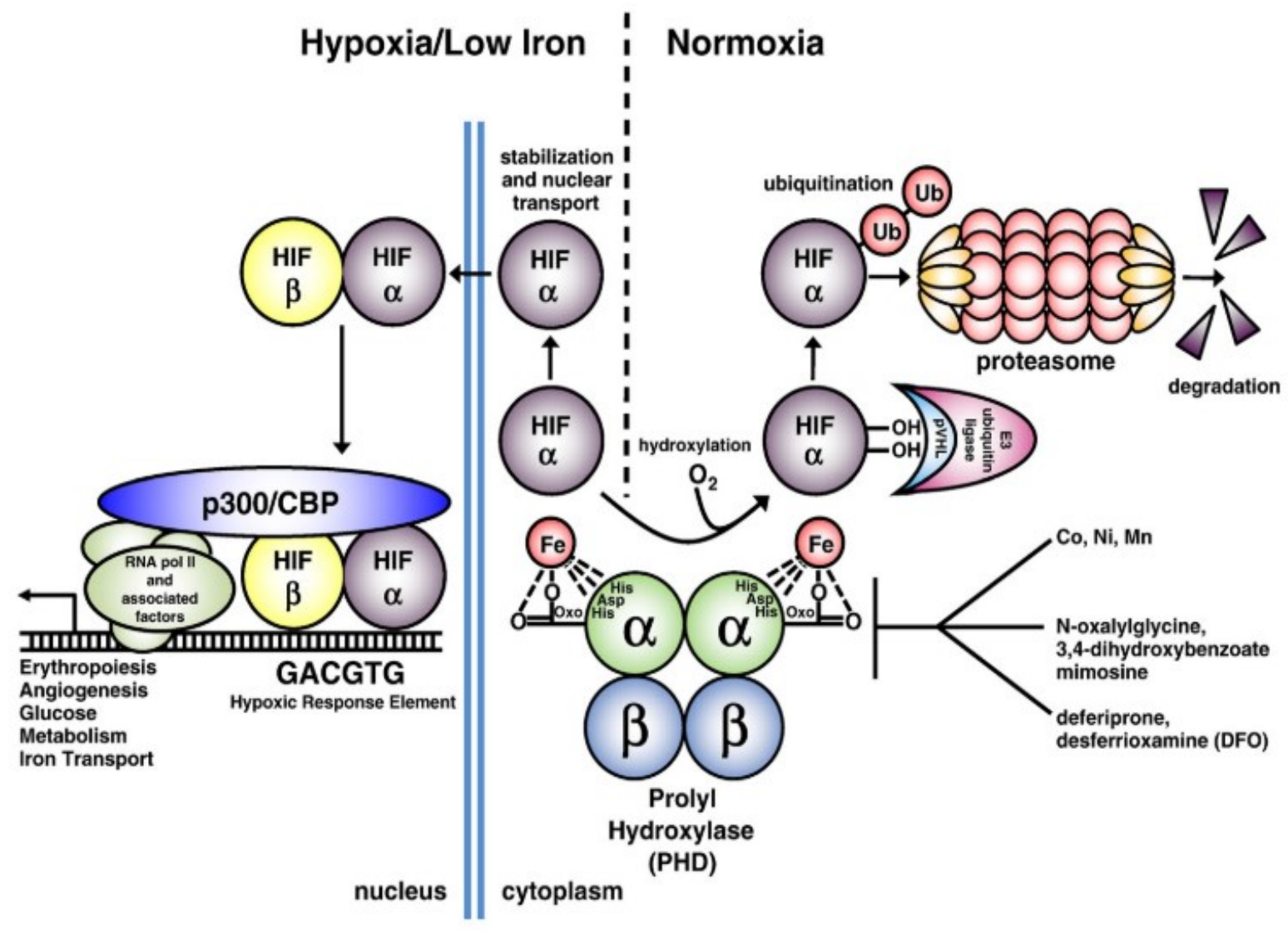


Figure 3: Oxygen- and iron-dependent regulation of HIF transcription factors.

HIF-1, -2 , and -3 are controlled at the protein level through hydroxylation and ubiquitin-dependent proteasomal degradation of their $\alpha$ subunits. Prolyl hydroxylase domain-containing hydroxylases (primarily PHD2) require iron, oxygen, 2-oxoglutarate, and ascorbate to hydroxylate HIF $\alpha$ at Pro residues, which favors the interaction ofhydroxylated HIF $\alpha$ with pVHL and its ubiquitination and proteasomal degradation. Various PHD inhibitors stabilize HIFas by preventing their hydroxylation. PHD inhibitors include transitional metals $(\mathrm{Co}, \mathrm{Ni}, \mathrm{Mn})$, which substitute for Fe2+ at the active site; iron chelators (deferiprone, desferrioxamine); and 2-oxoglutarate analogs. (Chepelev and Willmore, 2011) 

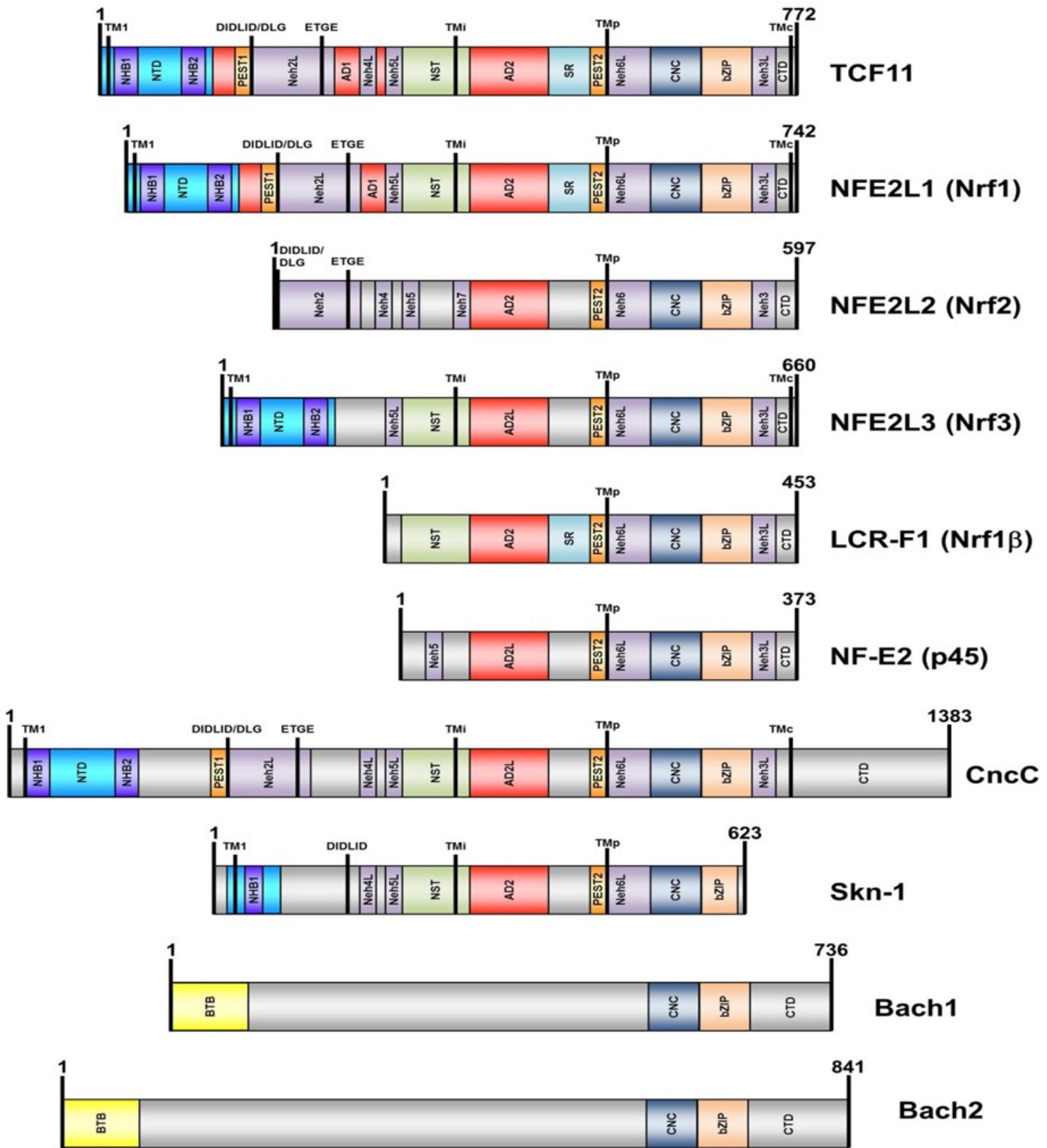
Figure 4: The cap'n'collar family of transcription factors and their common structural domains.

The human TCF11, Nrf1, Nrf2, Nrf3, LCR-F1 and NF-E2p45 proteins are shown in comparison to the Drosophila melanogaster $\mathrm{CncC}$ and Caenorhabditis elegans Skn-1 proteins, as well as the Nrf2 inhibitors, Bach1 and Bach2. All family members have a cap'n'collar (CNC) and basicleucine zipper (bZIP) domain present in the C-terminal domain (CTD) of the protein. The Nterminal domain (NTD) of many family members contains the N-terminal homology box 1 and 2 (NHB1 and NHB2 respectively) regions. Activators have Acidic Domains 1 and 2 (AD1 and AD2 respectively). The AD2L domainis present in Nrf3 only. Asn/Ser/Thr-rich (NST) and serine repeat (SR) domains are present in some, but not all, activators. The NST regions contain the sites for glycosylation in the family members that contain them. One or two Pro/Glu/Ser/Thrrich (PEST) sequences are present in many family members. Transmembrane domains include transmembrane 1 (TM1), the intermediate transmembrane (TMi), the amphipathic semihydrophobic transmembrane (TMp) and the C-terminal transmembrane (TMc) domains. This family of proteins are also characterized by up to 7 highly conserved Nrf2-ECH homology like domain (NehL) domains (labeled Neh1L to Neh7L or Neh1 to Neh7). The DIDLID/DLG element and ETGE motif regulate protein stability in the family members in which they are found. The Nrf2 repressors, Bach1 and Bach 2, contain a broad complex, tramtrack, bric-a-brac (BTB) domains which are atypical of other CNC family member proteins. Modified from Zhangetal.2014 (Bugno et al., 2015) 

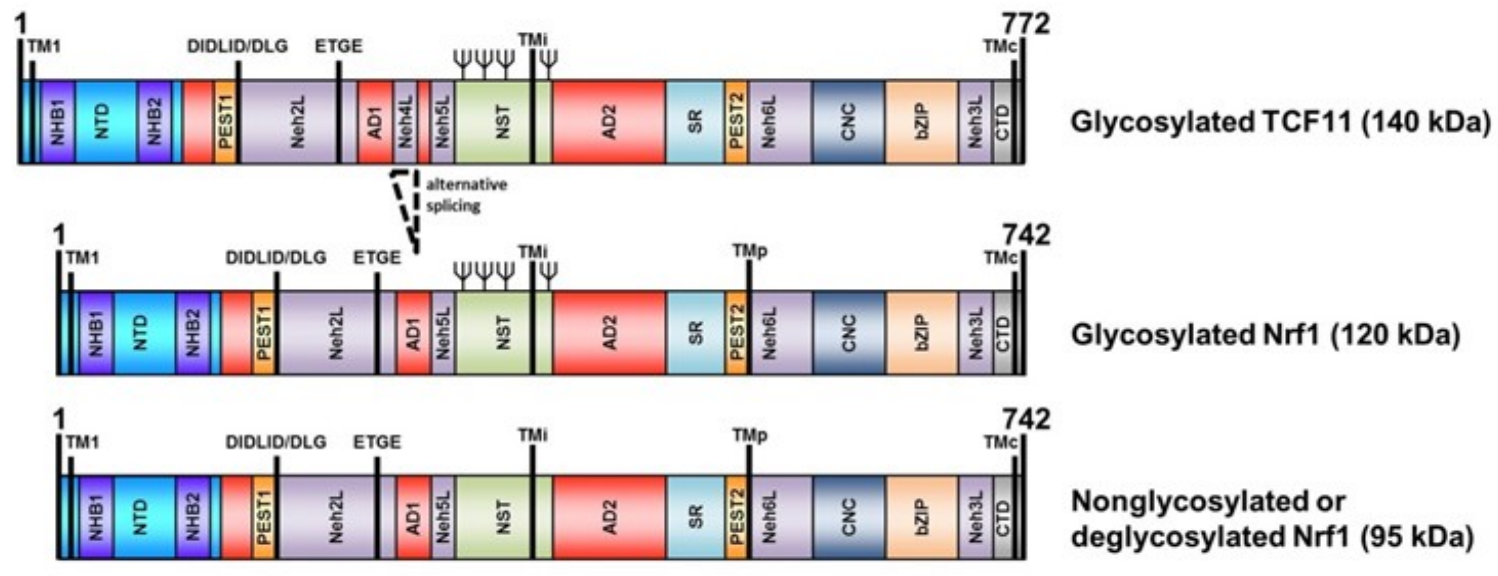

Nonglycosylated or deglycosylated Nrf1 (95 kDa)

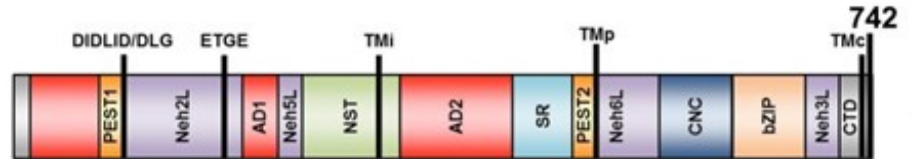

Cleaved Nrf1 $\triangle \mathrm{N}(85 \mathrm{kDa})$

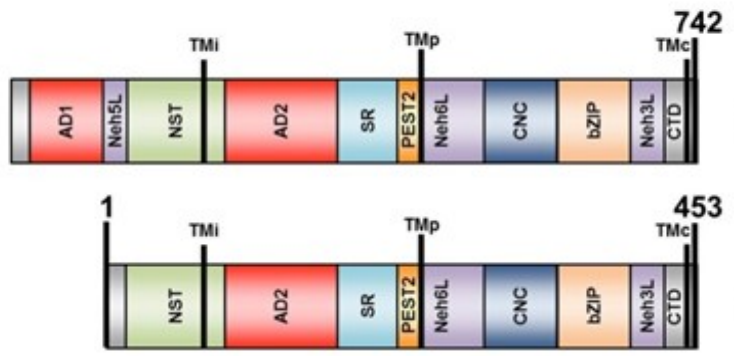

Cleaved Nrf1 (65 kDa)

LCR-F1/Nrf1 $\beta$ (55 kDa)

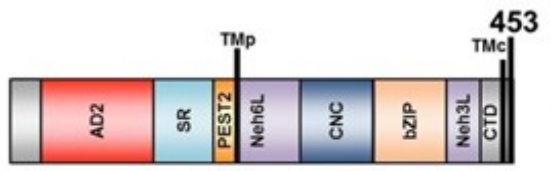

Cleaved Nrf1 $\beta$ (46 kDa)

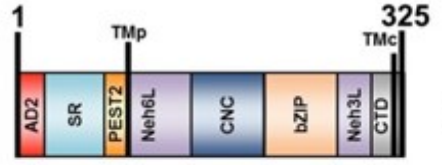

$\operatorname{Nrf1\gamma }(36 \mathrm{kDa})$

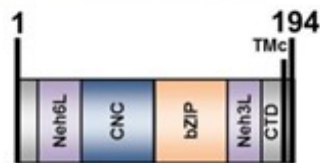

Nrf1 (25 kDa)

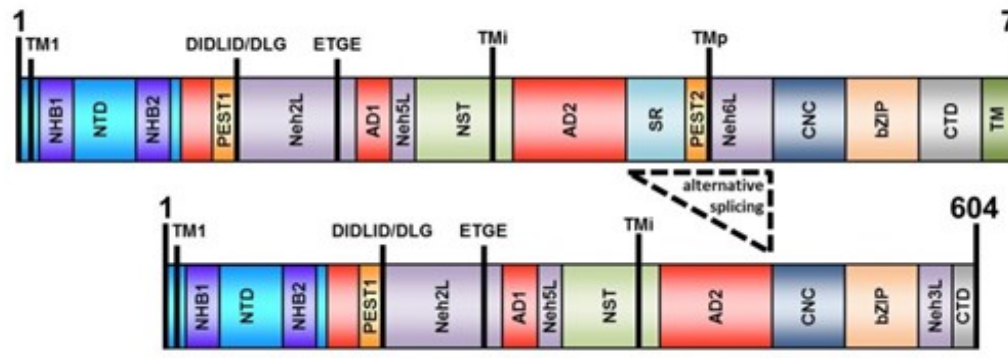

Nrf1D (98 kDa)

$\mathrm{Nrf1} \Delta \mathrm{S}$ (78 kDa) 
Figure 5: The multiple forms and cleaved products of Nrfl.

Full length and fully glycosylated Nrfl (p120) is created by alternate splicing of TCF11 (p140) which removes the Neh4L domain. Non-glycosylated Nrf1 (p95) is then proteolytically processed (possibly by apartially inhibited proteasome) to form all other cleaved products (p85, p65, p55, p46, p36 and p25). p55, p36 and p25 are also known as LCR-F1/Nrf1 $\beta$, Nrf $\gamma$ and Nrfo respectively. Nrf $\gamma$ and Nrf $\delta$ actasdominant-negative inhibitors of the CNC proteins as they compete with all other family members [Figure 4]. Nrf1D and Nrf1 $\Delta$ S are found to be alternatively expressed forms of Nrf1. Nrf1 $\Delta \mathrm{S}$ is created by alternative splicing of Nrf1D which removes the SR, PEST2 and Neh6L domains. All domains and motifs are labeled as in Figure 4. Modified from Zhangand Hayes 2013 (Bugno et al., 2015) 
Table 1: Protein functional domains of humanNFE2L1 (Nrf1). Amino acid residues are numbered according to the full length (p120) protein (adapted from Bugno et al., 2015)

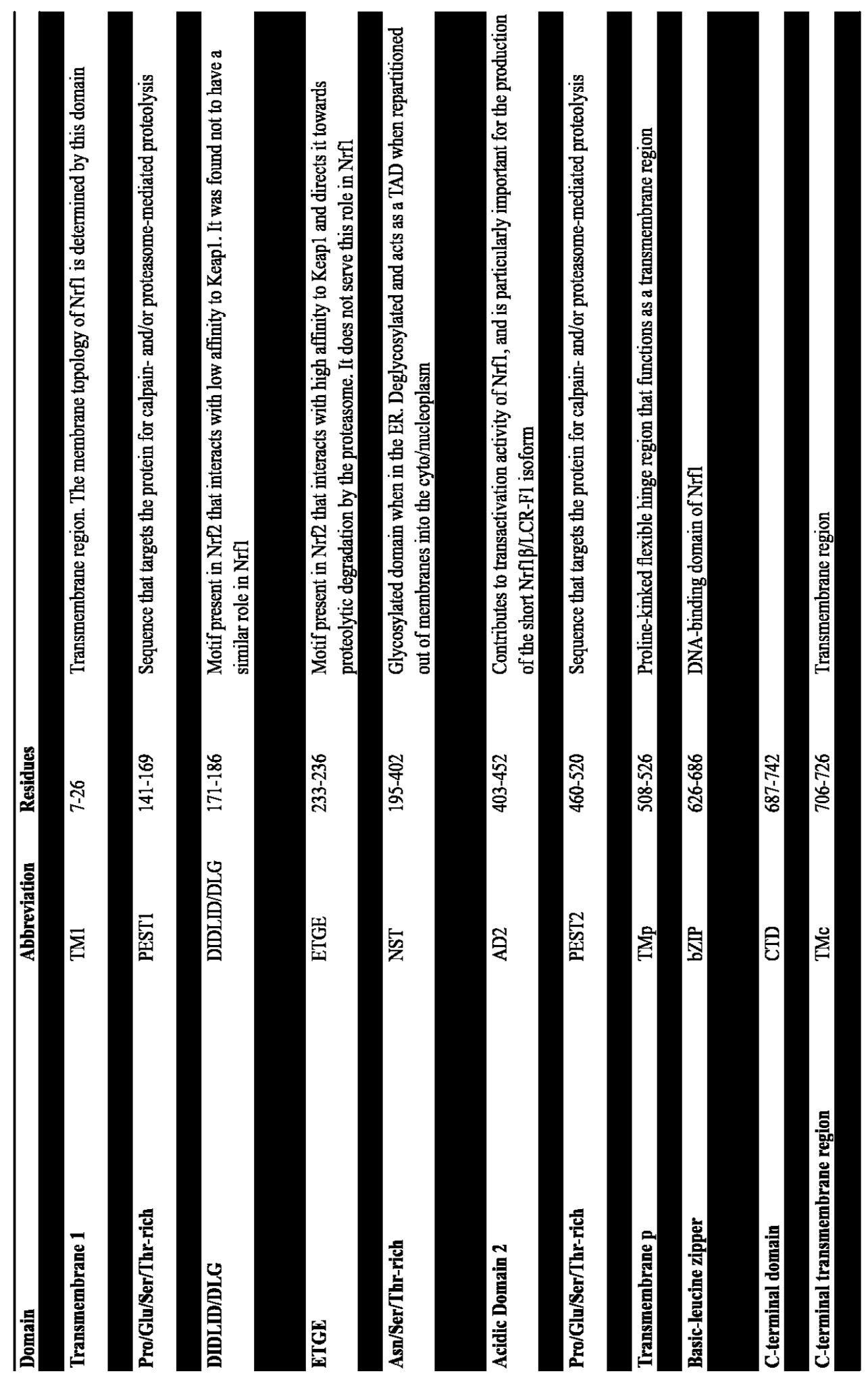




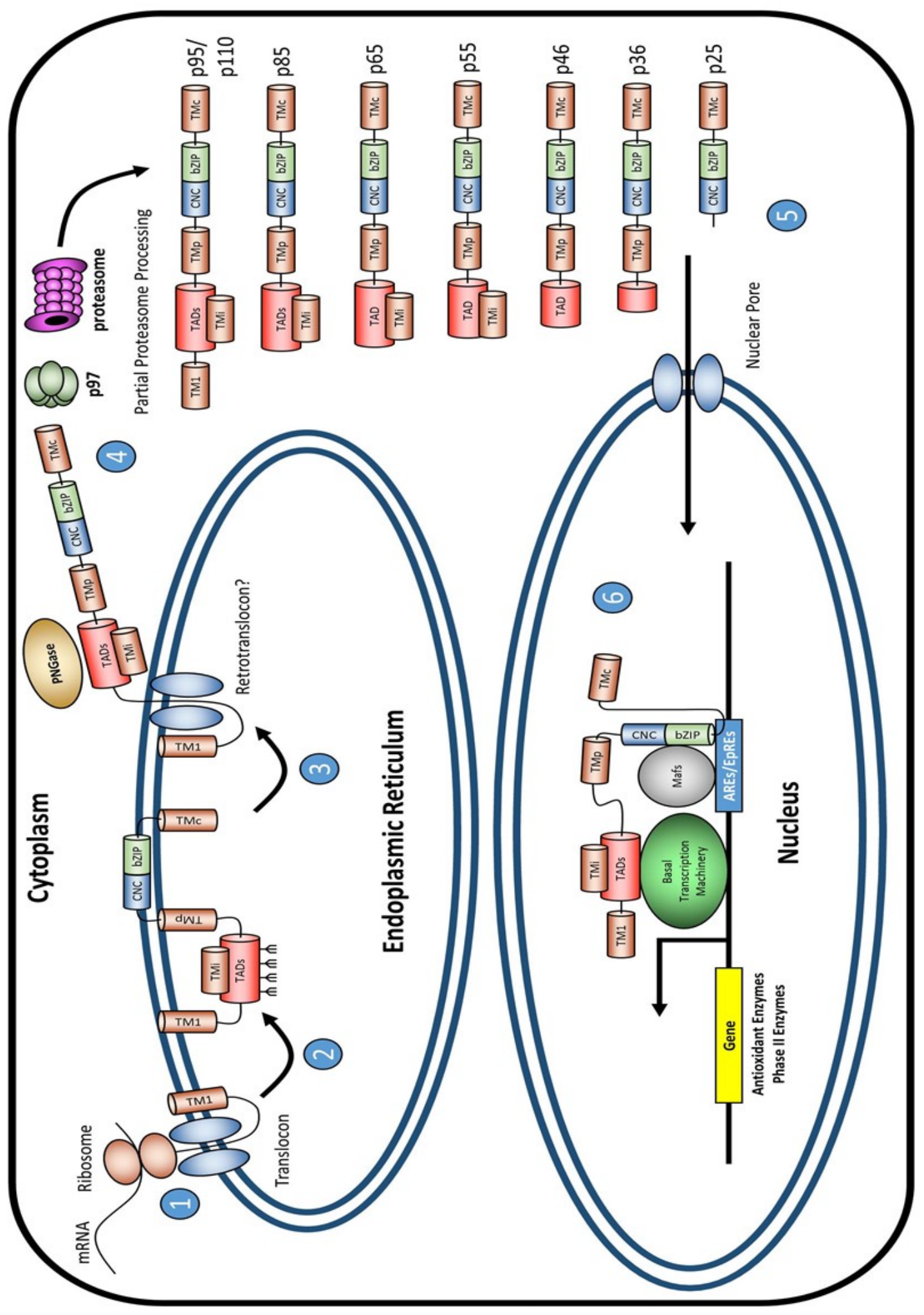


Figure 6: Proposed mechanisms by which Nrfl activates ARE/EpRE-responsive gene expression.

(1) Translation by the ribosome at the rough ER allows Nrf1 to be inserted directly into the ER once it moves through the translocon. (2) The NST domain and TADs are transiently translocated into the ER lumen where they are glycosylated to form p120-Nrf1. (3) p120-Nrf1 is repartitioned across the ER membrane where it is deglycosylated in the cytoplasm by PNGase, generating p95Nrf1. In endoplasmic reticulum-associated degradation (ERAD) (4) Nrf1 associates with the ERAD complex (p97/VCP and Hrd1) and is partially processed by a partially inhibited proteasome to generate the deglycosylated and truncated versions of the full-length protein (p95/p110, p85, p65, p55, p46, p36 andp25), which are assisted though the nuclearpore (5).Of these, p46, p36 and p25 are inhibitors of ARE/EpRE function. (6) Active and inactive forms of Nrf1 interact with small Maf proteins though their CNC-bZIP domains and associate with the AREs/EpREs. The TADs of active forms of $\mathrm{Nrfl}$ associate with the basal transcription machinery and activation of antioxidant and phaseII detoxification enzyme gene expression can occur. Nrf1 is also degraded in the nucleus via $\beta$-TrCP-mediated degradation ( $\beta$-TrCP, Skp1, ubiquitin and nuclear proteasomes). (Bugno, et al., 2015) 


\section{CHAPTER 2 MATERIALS AND METHODS}

\subsection{Mutagenesis}

Stratagene's QuickChange Site-Directed Mutagenesis Kit (Stratagene, La Jolla, California) was used to switch the $\mathrm{C}$ residue of the Proline codon $(\underline{\mathrm{CCC}})$ to a $\mathrm{G}$ residue of the Alanine codon ( $\underline{\mathrm{GCC}}$ ) (g.1843C $>\mathrm{G})$ to obtain the P398A mutation in Nrf1 protein sequence. Mutagenic primers were designed according to instruction manual of the kit and both forward and reverse primers were obtained from Integrated DNA Technologies. The double stranded DNA plasmid template was prepared with wildtype Nrf1 inserted in the E. coli plasmid vector pCR3.1.

Briefly, mutagenesis was carried out via PCR reaction containing $5 \mu \mathrm{L}$ of $10 \mathrm{x}$ reaction buffer, $50 \mathrm{ng}$ of dsDNA template, $125 \mathrm{ng}$ of forward primer, $125 \mathrm{ng}$ of reverse primer, $1 \mu \mathrm{L}$ of dNTP mix and double-distilled water $\left(\mathrm{ddH}_{2} \mathrm{O}\right)$ was added to a final volume of $50 \mu \mathrm{L}$, then $1 \mu \mathrm{L}$ of pfuTurbo DNA polymerase $(2.5 \mathrm{U} / \mu \mathrm{L})$ was added. Along with sample reactions, a control reaction was also prepared to check mutagenesis efficiency. Cycling parameters for PCR reactions were carefully set and ran following the manual. Amplification products was then treated with $1 \mu \mathrm{L}$ of DpnI endonuclease (targets $5^{\prime}-\mathrm{Gm}^{6} \mathrm{ATC}-3^{\prime}$ ) to digest the parental DNA template. Transformation was performed by transferring $1 \mu \mathrm{L}$ DpnI-treated DNA products from each control and sample reaction to separate XL1-Blue supercompetent cells aliquots followed by adding $0.5 \mathrm{~mL}$ of $\mathrm{NZY}^{+}$broth. Cells were then spread on LB-ampicillin agar plates containing $80 \mu \mathrm{g} / \mathrm{mL}$ X-gal and $20 \mathrm{mM}$ IPTG and incubated for 16 hours at $37^{\circ} \mathrm{C}$. Mutagenesis efficiency was accessed by blue and white colonies screening from control reaction. Colonies obtained from sample reactions were picked, cultured and stored for later use. Plasmids were purified from bacteria using a Wizard Plus Midipreps DNA Purification System (Promega, Madison, 
Wisconsin) was also performed at the same time for restriction digest and sequencing (Biobasic

Sequencing, Markham, Ontario) purpose. $1 \mu \mathrm{L}$ of each of two restriction enzymes, EcoRI and

NdeI, were mixed with $1 \mu \mathrm{g}$ of DNA products, $2 \mu \mathrm{L}$ of Cutsmart Buffer (New England Biolabs, Ipswich, Massachusetts) and Milli-Q $\mathrm{H}_{2} \mathrm{O}$ to make a $20 \mu \mathrm{L}$ total reaction volume. The digested DNA was then examined with a $1 \%$ agarose gel.

\subsection{Cell Culture and Sample Preparation}

\subsubsection{Cell Culture}

Human embryonic kidney 293T cells (HEK293T) from the American Tissue Culture Collection (ATCC, Manassas, Virginia) was cultured in complete media consisting of Dulbecco's Modification Eagle's Medium 1X (DMEM) (Wisent, Saint-Jean-Baptiste, Quebec) supplemented with $10 \%$ Fetal Bovine Serum (FBS) (ThermoFisher Scientific, Ottawa, Ontario), at $37^{\circ} \mathrm{C}$ in a $5 \%$ $\mathrm{CO}_{2}$ and $21 \% \mathrm{O}_{2}$ atmosphere (Thermo Forma Series II Incubator, Waltham, Massachusetts). Cells were passaged every 3 days. Cells were rinsed with sterile PBS (pH 7.5), $1 \mathrm{~mL}$ Trypsin $(0.25 \%$ in PBS) was then added covering the cells for trypsinization at $37^{\circ} \mathrm{C}$ for $3-5$ minutes followed with $9 \mathrm{~mL}$ of complete media. Cells were then spun down in sterile $50 \mathrm{~mL}$ Falcon tube at $2000 \mathrm{rpm}$ and cell pellet was resuspended in fresh new media and dispensed back in the original culture flask.

\subsubsection{PEI Transfection and DNA Plasmids}

To deliver both wildtype and mutant Nrf1 DNA plasmids in HEK293T cells, a stable cationic polymer, polyethylenimine (PEI) was used as it forms positively charged complex with 
DNA, which then binds to anionic cell surface and ultimately leads to endocytosis, by which DNA:PEI complex enters the cell and DNA is released.

PEI (Sigma-Aldrich, St. Louis, Missouri) working solution was prepared at the concentration of $1 \mathrm{mg} / \mathrm{mL}, \mathrm{pH} 7.0$. PEI transfection efficiency was checked using green fluorescent protein (GFP) DNA plasmid, 6-well tissue plate containing HEK293T cells were transfected with $4 \mu \mathrm{g}$ of GFP plasmid and varied amount of PEI working solution $(0,5,10,15,20,25 \mu \mathrm{L})$, transfection efficiency was evaluated by percentage of GFP transfected 24 hours later under microscope.

Briefly, cells were at least $70-80 \%$ confluent before transfection and DNA plasmids were extracted and purified by midiprep. Nrfl gene constructs were obtained by cloning the region of interest into the PCR3.1 plasmid vector. For Western blotting, pUC19, HA-EGLN1-pcDNA3 (obtained from Kaelin Lab), wildtype Nrf1, mutant Nrf1 were used for transfection. In two separate tubes, $10 \mu \mathrm{g}$ of total amount of DNA (5 $\mu \mathrm{g}$ of each DNA plasmid was used for co-transfection) was added in $250 \mu \mathrm{L}$ of Opti-MEM (Rescued Serum Medium, ThermoFisher Scientific, Ottawa, Ontario) and $25 \mu \mathrm{L}$ of PEI working solution was mixed with $250 \mu \mathrm{L}$ of Opti-MEM, diluted PEI solution was then transferred into DNA dilution, they were incubated for a period of 15 minutes and vortexed every 3 minutes. The PEI:DNA complex was added dropwise in the plate. For luciferase assay, pGL4.37 [Luc2p/ARE/Hygro] (obtained from Promega), $\beta$-gal, pUC19, HAEGLN1-pcDNA3, wildtype Nrf1, mutant Nrf1 were used, following protocol described above except the control or target DNA plasmids $(1 \mu \mathrm{g})$ were co-transfected with $9 \mu \mathrm{g}$ of pGL4.37 and $0.4 \mu \mathrm{g}$ of $\beta$-gal. For co-immunoprecipitation, $10 \mathrm{~cm}$ plates were used, total amount of DNA and PEI working solution were increased to $20 \mu \mathrm{g}$ and $54 \mu \mathrm{L}$ respectively and were diluted in $500 \mu \mathrm{L}$ of Opti-MEM. 


\subsection{Hypoxia Treatment}

HEK293T cells were plated in $6 \mathrm{~cm}$ plates one day before the hypoxia treatment. Following the transfection on second day, cells were treated with hypoxia condition at $37^{\circ} \mathrm{C}$ in a $5 \% \mathrm{CO}_{2}$ and $1 \% \mathrm{O}_{2}$ atmosphere (Thermo Forma Series II Incubator, Waltham, Massachusetts) before harvest. Cells were treated for $0,1,2,4,8,16,24$ and 48 hours with hypoxia to test change in Nrf1 expression for both endogenous and overexpressed samples. Hypoxia treatment (24 hours) was used for later experiments in Western blotting, luciferase assay and co-immunoprecipitation.

\subsection{Cell Harvest, Whole-Cell Lysis and Sample Preparation}

For Western blotting, cells were rinsed twice with pre-warmed PBS and lysed in $100 \mu \mathrm{L}$ of cold RIPA buffer (Pierce ${ }^{\mathrm{TM}}$, ThermoFisher Scientific, Ottawa, Ontario) on ice. After transferring cell lysate to Eppendorf tubes, cell lysate was incubated in $4^{\circ} \mathrm{C}$ cold room for 30 minutes on a rotator and then was spun at $17,000 \mathrm{x} g$ for 15 minutes. Supernatant containing total protein was retained and stored at $-80^{\circ} \mathrm{C}$ for later experiments.

Cells were harvested and lysed in the similar manner for Luciferase assay, except a different lysis buffer containing $25 \mathrm{mM}$ glycylglycine, $15 \mathrm{mM} \mathrm{KH}_{2} \mathrm{PO}_{4}, 15 \mathrm{mM} \mathrm{MgSO}_{4}, 4 \mathrm{mM}$ EDTA, 1 mM DTT, 1\% Triton X-100 and 1 x Protease Inhibitor Cocktail, Mammalian (Bioshop, Burlington, Ontario) was prepared and $50 \mu \mathrm{L}$ lysis buffer was used to lyse the cells.

Lysis buffer used for co-immunoprecipitation was 1x PBS (pH 7.5) containing $5 \mathrm{mM}$ EDTA, $0.02 \%$ sodium azide, $20 \%$ glycerol and $1 \%$ Triton X-100. Cells were harvested and lysed the same manner as described above in $800 \mu \mathrm{L}$ lysis buffer. 


\subsection{Western Blotting}

\subsubsection{Western Blotting and Antibodies}

Total protein concentration was quantified using BCA assay $\left(\right.$ Pierce $^{\mathrm{TM}}$, ThermoFisher Scientific, Ottawa, Ontario, Canada) protocol. $30 \mu \mathrm{g}$ of total protein was mixed with 2 X SDS loading buffer (Bio-Rad, Hercules, California) and was boiled at $95-100^{\circ} \mathrm{C}$ for 5 minutes before loaded into $10 \%$ gel for SDS-PAGE, next to the lane loaded with All-Blue Protein Ladder (BioRad, Hercules, California) for protein molecular weight determination. The gel containing $0.5 \%$ tricholoroethanal (TCE) (Sigma-Aldrich, Hercules, California) was allowed to run for 1 hour and 50 minutes at $120 \mathrm{~V}$, followed by overnight transfer of protein from the gel onto PVDF membrane (Bio-Rad, Hercules, California) at $4{ }^{\circ} \mathrm{C}$.

Membrane was blocked with $5 \%$ non-fat milk for 1 hour at room temperature, followed by 30 minutes of incubation with the primary antibody and then 30 minutes incubation with secondary antibody. Primary antibodies were diluted into TBST containing $5 \%$ BSA and $0.1 \%$ sodium azide while secondary antibodies were diluted into TBST with $5 \%$ BSA as follows: antiNrf1 polyclonal rabbit (Novus Biologicals, Oakville, Ontario): 1 in 1500, anti-EGLN1/PHD2 polyclonal rabbit (Novus Biologicals, Oakville, Ontario): 1 in 2,000, polyclonal goat antipolyclonal rabbit-HRP (Abcam, Cambridge, Massachusetts): 1 in 15,000, polyclonal goat antimouse-HRP (Dako Denmark), 1 in 5,000.

\subsubsection{Densitometry}

Densitometry was performed by the Image Lab 6.0 software (Bio-Rad, Hercules, Massachusetts). Boxes of equal and minimal areas were drawn for each band and normalized to 
total protein loaded in each lane. Each integrated density value (IDV) value was normalized to controls. Normalized data was then analyzed for statistical significance.

\subsection{Luciferase assay}

The pGL4.37 [luc2P/ARE/Hygro] Vector containing luciferase gene was used to measure activation of the AREs in cells upon treatment with hypoxia while beta-galactosidase ( $\beta$-gal) was used as internal control.

Cells were lysed and assayed on the same day. Luciferase enzymatic activity was examined by combining $10 \mu \mathrm{L}$ fresh cell lysate and $76 \mu \mathrm{L}$ luciferase assay buffer in a 96-well white plate followed by the injection of $50 \mu \mathrm{L}$ luciferin solution (Promega, Madison, Wisconsin). Luminescence of each well was measured by FLUOstar OPTIMA microplate reader. $\beta$-gal assay was performed by combining $50 \mu \mathrm{L}$ luciferase lysate from the white plate with $85 \mu \mathrm{L} \beta$-gal assay buffer in a clear bottom 96 -well plate for a 30 minutes incubation at $37^{\circ} \mathrm{C}$. Plates were read at 570 $\mathrm{nm}$ with a background subtraction at $630 \mathrm{~nm}$. Averaged readings from untransfected samples were subtracted from the rest of transfected ones in both assays. Luminescence readings were then divided by $\beta$-gal values to obtain the final data.

\subsection{Co-Immunoprecipitation}

\subsubsection{DSP (dithiobis[succinimidylpropionate]) Crosslinker Treatment}

DSP (dithiobis[succinimidylpropionate]) was used to crosslink highly nucleophilic surface

lysine residues in relative close proximity (11.4 $\AA$ to $12 \AA)$. Cells were treated with DSP to 
examine proteins that may have close interactions with target Nrf1 protein, which later can be pulled down as a protein complex with Nrf1 via immunoprecipitation.

Briefly, $50 \mathrm{mg}$ of DSP (ThermoFisher Scientific, Ottawa, Ontario) was dissolved in 500 $\mu \mathrm{L}$ dry DMSO giving a stock concentration of $247.26 \mathrm{mM}$. Stock DSP solution was then mixed with $60 \mathrm{ml}$ pre-warmed $\left(37^{\circ} \mathrm{C}\right) \mathrm{PBS}$, giving a final concentration of $2.06 \mathrm{mM}$. In each $10 \mathrm{~cm}$ plate,

cells were treated with $6 \mathrm{~mL}$ DSP solution for 30 minutes at room temperature, followed by adding $120 \mu \mathrm{L}$ of $1 \mathrm{M}$ Tris Stop Solution for 15 minutes. Discard liquid in the plate, cells were rinsed three times by warm PBS.

\subsubsection{Co-Immunoprecipitation}

Lysis buffer used for co-immunoprecipitation was 1 x PBS (pH 7.5) containing $5 \mathrm{mM}$ EDTA, $0.02 \%$ sodium azide, $20 \%$ glycerol and $1 \%$ Triton X-100. Cells were lysed in $800 \mu \mathrm{L}$ cold lysis buffer followed by a 1 hour incubation on a rotator at $4^{\circ} \mathrm{C}$ and then spun down at 17,000 $\mathrm{x} \mathrm{g}$ for 15 minutes.

Protein lysate $(500 \mu \mathrm{L})$ was precleared with $80 \mu \mathrm{L}$ protein A/G beads (Santa Cruz Biotechnology, Dallas, Texas) and $0.5 \mu \mathrm{g}$ Rabbit IgG Isotope Control (Novus Biologicals, Oakville, Ontario) for 2 hours at $4^{\circ} \mathrm{C}$, and then was spun down at $500 \mathrm{x}$ g for 5 minutes at $4^{\circ} \mathrm{C} .0 .5$ $\mu \mathrm{g}$ anti-Nrf1 polyclonal rabbit (Novus Biologicals, Oakville, Ontario) was mixed with precleared lysate and incubate for 18 hours at $4^{\circ} \mathrm{C}$. Protein A/G beads $(80 \mu \mathrm{L})$ was then added for an additional 4 hours incubation at $4^{\circ} \mathrm{C}$. The mixture was spun down at $500 \mathrm{xg}$, the pellet was saved and washed three times with PBS.

Glycine- $\mathrm{HCl}$ elution buffer $(150 \mu \mathrm{L}$ of $0.2 \mathrm{M} ; \mathrm{pH} 2.8)$ was added to the beads. After $5-10$ minutes of incubation with frequent agitation, $150 \mu \mathrm{L}$ of $1 \mathrm{M}$ Tris buffer $(\mathrm{pH} 8.0)$ was added for 
neutralization. The beads were then centrifuged at $800 \mathrm{xg}$ and the eluate was collected in fresh tube.

Eluted samples were injected into dialysis cassette (3.5K MWCO; $0.5 \mathrm{~mL}$; ThermoFisher, Ottawa, Ontario) and submerged in Milli-Q water for 2 hours at $4^{\circ} \mathrm{C}$. Another 2 hours incubation was repeated once with fresh Milli-Q water before a third overnight incubation in fresh Milli-Q water at $4^{\circ} \mathrm{C}$. Dialyzed samples were withdraw from the cassette and dry down using speed vac.

\subsubsection{Mass spectrometry}

10ug of protein sample was reduced by DTT for 1 hour at $56^{\circ} \mathrm{C}$, followed by alkylation with IODO for 1 hour in the dark. 1 part of trypsin was mixed with 30 parts of protein for digestion overnight at $37^{\circ} \mathrm{C}$. The sample was then diluted with $0.1 \%$ formic acid with $1: 5$ ratio followed with 10ul sample injection with M Class Nanoacquity and MS/MS analysis using Synapt G2. Inhouse Human Protein Database was used for peptide fragments identification. Ion cut-off score was set above 30 .

\subsection{Statistical analysis}

All statistical comparisons were made relative to the controls using Sigmaplot software (San Jose, CA) with one-way ANOVA followed by the Dunnett's test. All values displayed in the figure represented the mean \pm the standard error of the mean (SEM) for a minimum of 3 independent experiments. Values were considered to be significantly different from one another if $\mathrm{p}<0.05$, designated by the “*” in the figure. 


\section{CHAPTER 3: RESULTS}

\subsection{Effects of Hypoxia On NFE2L1 (Nrf1) Protein Expression}

The expression profile of both endogenous and transfected NFE2L1 (Nrf1) in response to various exposure times of hypoxia were examined using Western blotting. Under non-transfected conditions, endogenous Nrf1 was present as four major isoforms, p140, p120, p95 and p85 [Figure 7 (a)]. In general, the levels of longer/inactive Nrf1 isoforms (p140 and p120) were lower than the shorter/active forms (p95 and p85). As the hypoxia treatment prolonged (0 to 48 hours), a significant shift between Nrf1 isoforms was observed, where the active p95 isoform steadily increased as the inactive p120 isoform decreased [Figure 7 (b)].

A similar time course of hypoxia treatment was performed with Nrf1 and PHD2 overexpressed in HEK293T cells [Figure 8 (a) and (b)]. The most predominant band observed corresponded to the molecular weight of p120 Nrf1. Shorter isoforms were barely seen in both wtNrf1 and mutNrf1 transfected samples and the absence of shorter isoforms became more evident when both wildtype and mutant Nrf1 was co-expressed with PHD2. All samples showed that the p120 isoform was stabilized as the hypoxia persisted. Among four different overexpression treatments, co-transfection of wtNrf1 and PHD2 was most responsive to the hypoxia treatment. The highest expression of p120 Nrf1 was seen at 8 hours of hypoxia treatment and the second highest signal was found at 24 hours of hypoxia treatment.

Transfected samples were then subjected to 24 hours of hypoxia treatment, in comparison to normoxia. The overexpression of Nrfl was significant, compared to endogenous and control samples [Figure 9 (a) and (b)]. As with other Nrf1 transfected samples, p120 showed strongest signal comparing to the other isoforms with the same condition. In general, the p120 isoform appeared to be stabilized with hypoxia treatment and the stabilization of p120 presented an upward 
trend when PHD2 was co-expressed. No significant difference in p120 was found under normoxic conditions except the mutNrf1 overexpressed sample showed a significant decline.

\subsection{Hypoxic Effects On PHD2}

A steady increasing trend was observed in the endogenous PHD2 expression in response to hypoxia treatment [Figure 10 (a) and (b)]. The overexpressed PHD2 containing a HA-tag showed up in the bands with a slower electrophoretic shift, which had a slightly higher molecular weight than the endogenous PHD2. A similar trend of endogenous PHD2 expression was found in these transfected samples [Figure 11 (a) and (b)]; the accumulation of PHD2 was significant over the course of the hypoxia treatment. Figure 11 also shows that, when Nrfl was co-expressed with PHD2, PHD2 expression was not significantly increased until 24 hours under hypoxia conditions. PHD2 also showed a sudden increase at 48 hours of hypoxia treatment.

Transfected samples were then subjected to 24 hours of treatment with either hypoxia or normoxia. Overexpression of PHD2 showed significantly higher PHD2 expression, compared to endogenous and control samples [Figure 12 (a) and (b)]. Interestingly, PHD2 expression was supressed when both wildtype and mutant Nrf1 were co-expressed. There was no significant difference of PHD2 expression observed with respect to different oxygen conditions at 24 hours.

\subsection{Effects Of Hypoxia On Nrf1 Functionality}

Luciferase reporter assay was used to evaluate the transactivation activity of Nrfl. In comparison to normoxia, at least a 1.5-fold increase in Nrf1 activity was observed after 24 hours hypoxia treatment in all Nrf1 overexpressed samples. The co-expression of PHD2 did not show significant effect on Nrf1 activity in both normal and low oxygen conditions [Figure 13]. 


\subsection{Nrf1 Co-Immunoprecipitation and Mass Spectrometry}

Co-immunoprecipitation was performed using anti-Nrfl antibody to determine if there was an interaction between Nrf1 and PHD2, as well as to capture Nrf1 interacting proteins. Mass spectrometry data was generated from five samples, kept in normoxia 24 hours post transfection: a) endogenous, b) wtNrf1 overexpressed, c) mutNrfl overexpressed, d) wtNrf1/PHD2 coexpressed and e) mutNrf1/PHD2 co-expressed samples. The Nrf1 protein was identified in wtNrf1 overexpressed (Mascot score of 108), mutNrf1 overexpressed (Mascot score of 50) and mutNrf1/PHD2 co-expressed (Mascot score of 49) samples [Table 2 (a)]. Table 2 (b) included the list of all proteins that were identified in all five samples. Interestingly, a ring-type E3 ubiquitinprotein ligase Praja-1 was identified in mutNrf1 transfected samples (Mascot score of 55) and it also appeared in mutNrf1/PHD2 co-expressed sample (Mascot score 43). There were no peptide fragments identified matching PHD2 protein sequence among all samples. The complete MS result summary table can be found in the Appendix. 
(a)

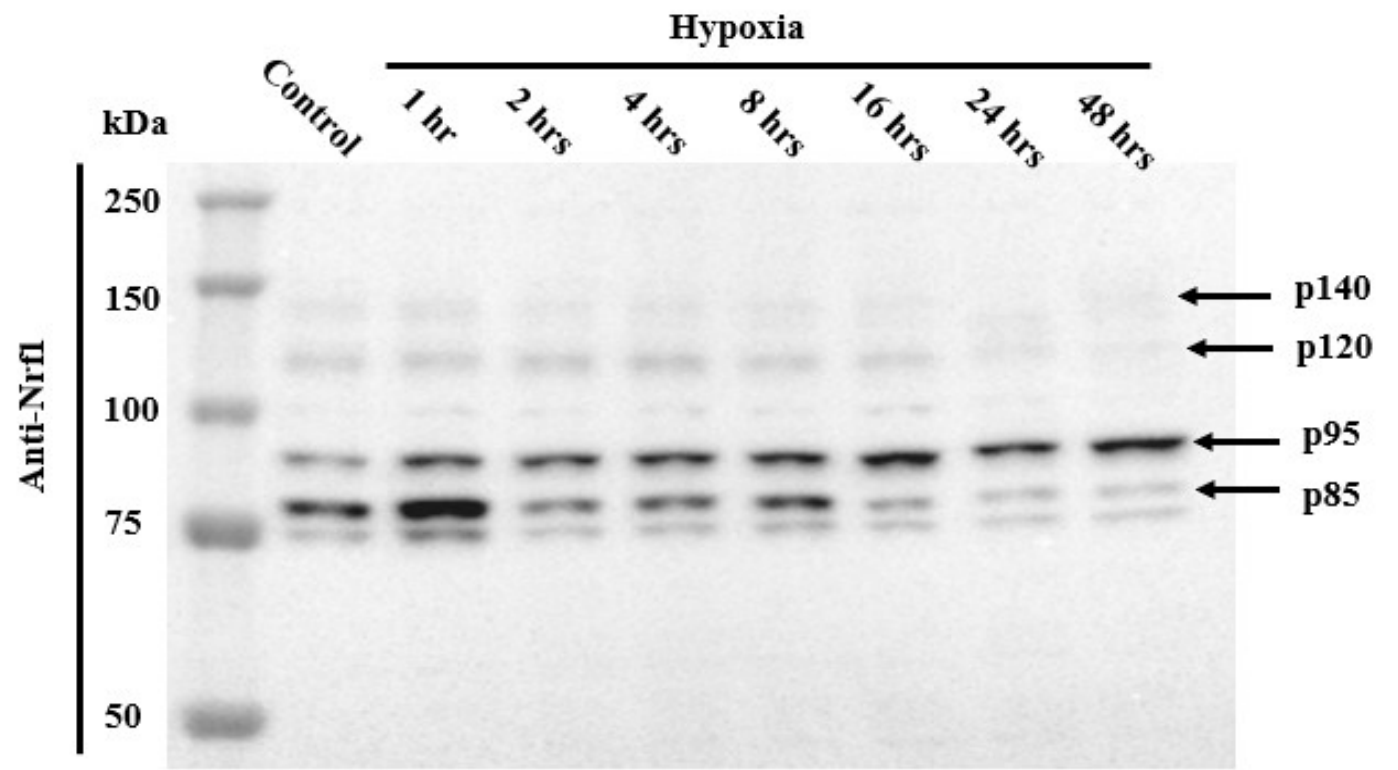

Beta-tubulin

(b)

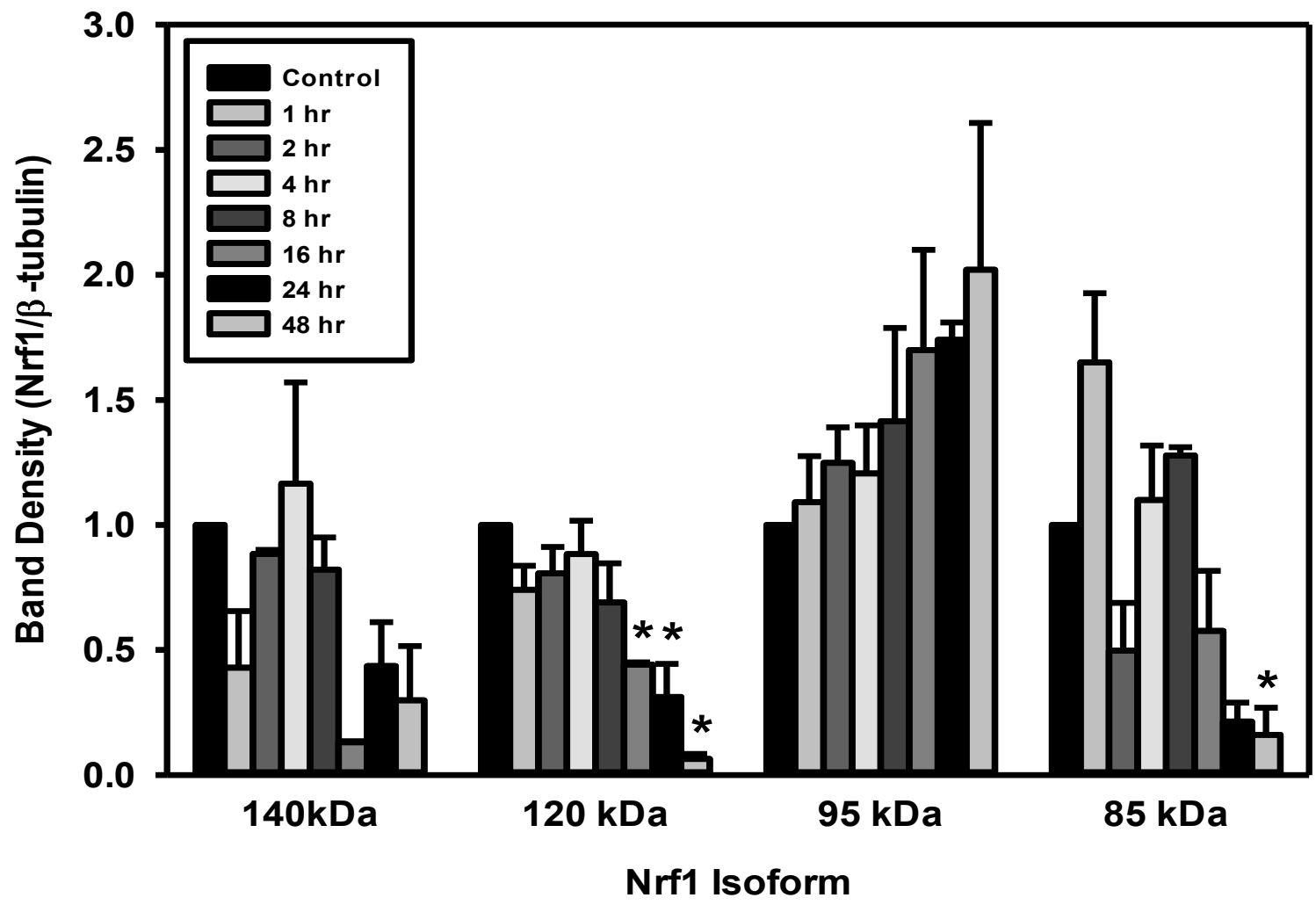


Figure 7: Western blot analysis of endogenous Nrfl protein expression profile in response to various durations of low oxygen $(1 \%)$ treatment.

Multiple bands corresponding to the molecular weight of Nrf1 isoforms, p140, p120, p95 and p85 during different period $(0,1,2,4,8,16,24,48$ hours $)$ of hypoxia $\left(1 \% \mathrm{O}_{2}\right)$ treatment in endogenous HEK293T cells. Band density values were normalized to total protein in each lane, as well as to the control signal. (a) Western blot presentation. (b) bar graph from densitometry data analysis. Dunnett's statistical test was performed to compared each of the treatment to control and significant difference were found with samples marked with “*” with a $p<0.05$. 
(a)

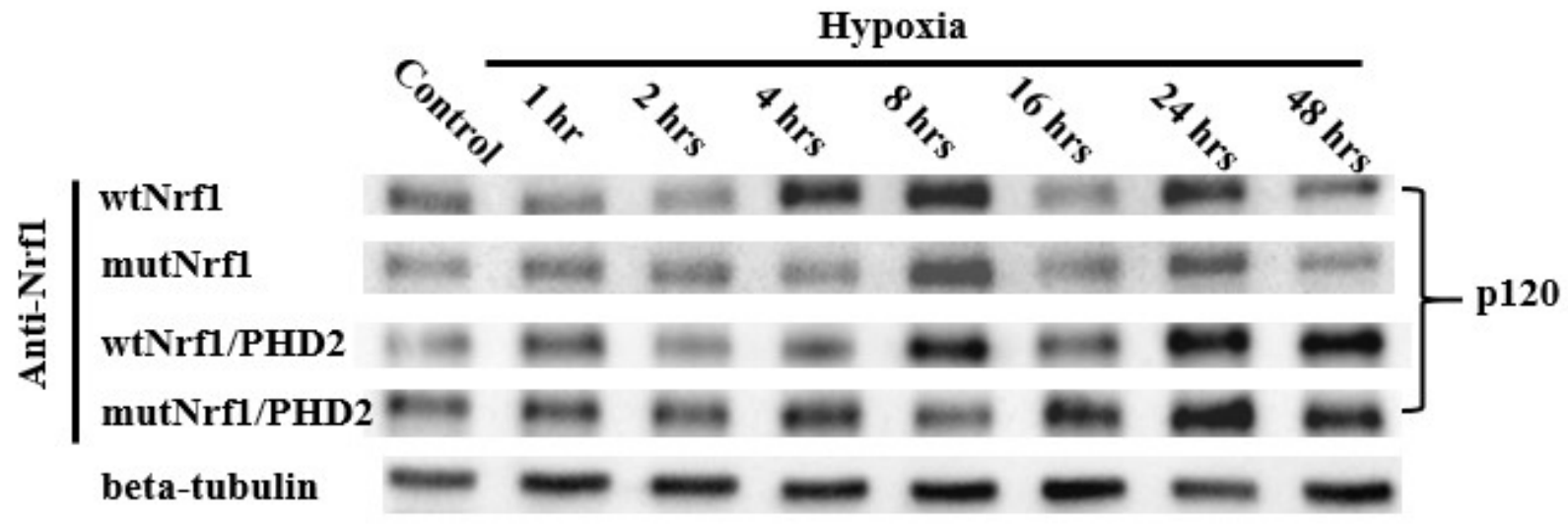

(b)

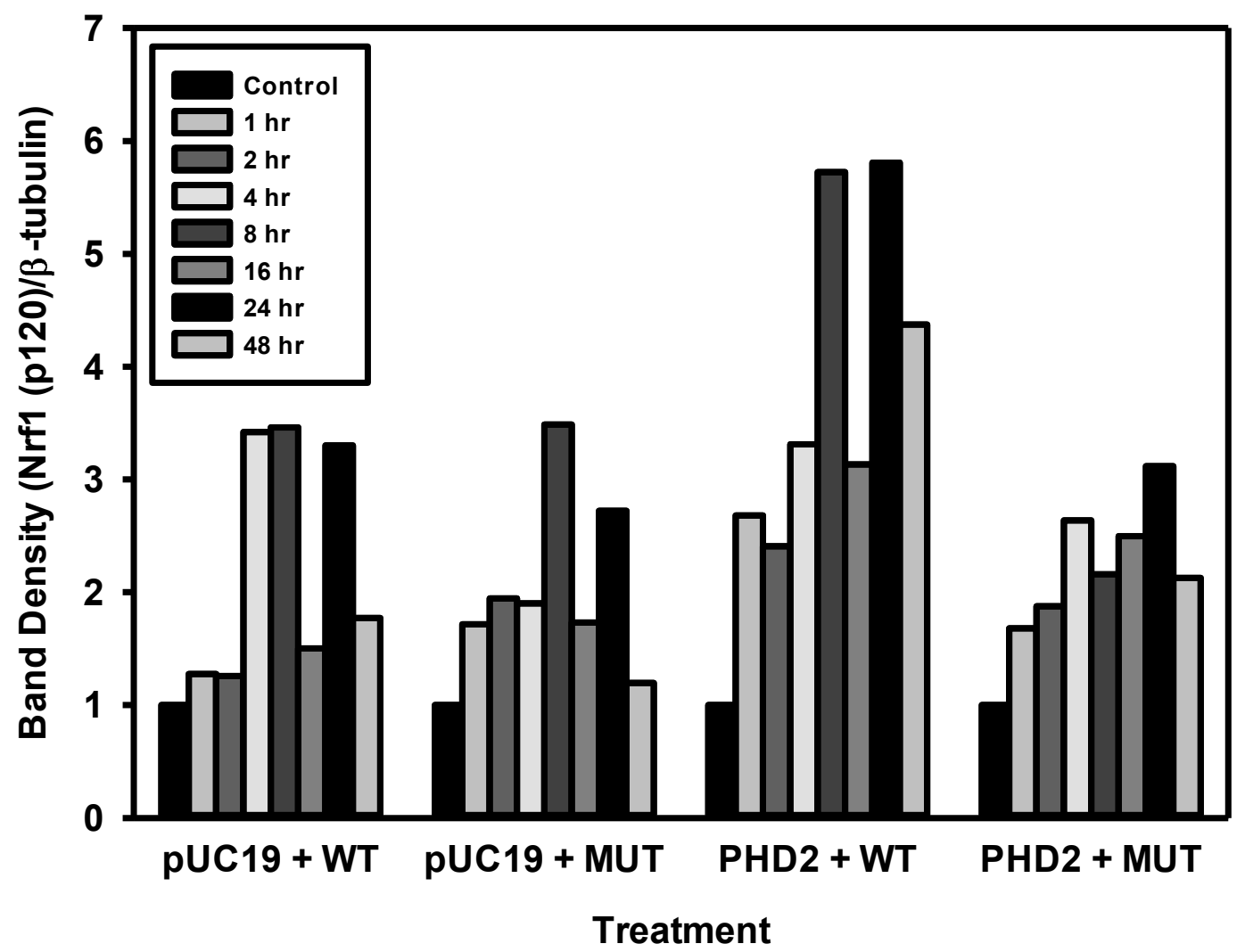


Figure 8: Western blot analysis of Nrfl protein expression in response to various durations of low oxygen (1\%) treatment in transient transfected HEK293T cells.

A predominant band corresponding to the molecular weight of Nrf1 isoform, p120 during different period $(0,1,2,4,8,16,24,48$ hours $)$ of hypoxia $\left(1 \% \mathrm{O}_{2}\right)$ treatment in transient transfected HEK293T cells (wtNrf1, mutNrf1, wtNrf1/PHD2 or mutNrf1/PHD2 overexpressed). Band density values were normalized to total protein in each lane, as well as to the control signal. (a) Western blot presentation. (b) bar graph from densitometry data analysis. 
(a)

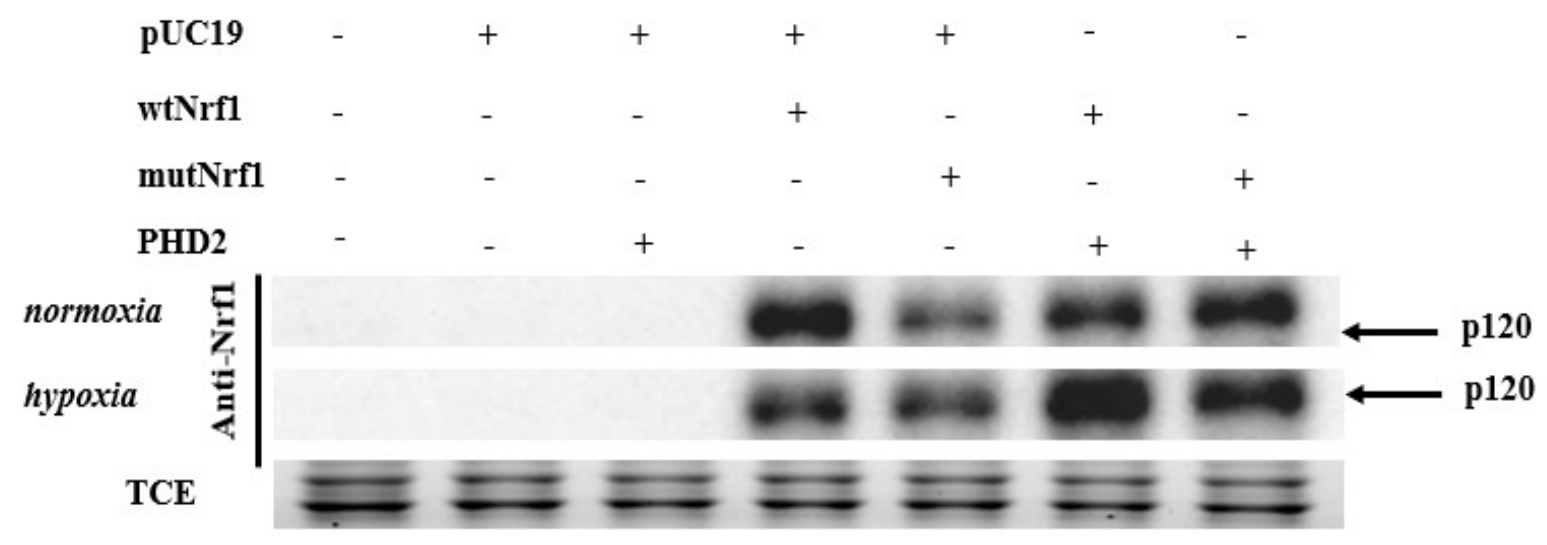

(b)

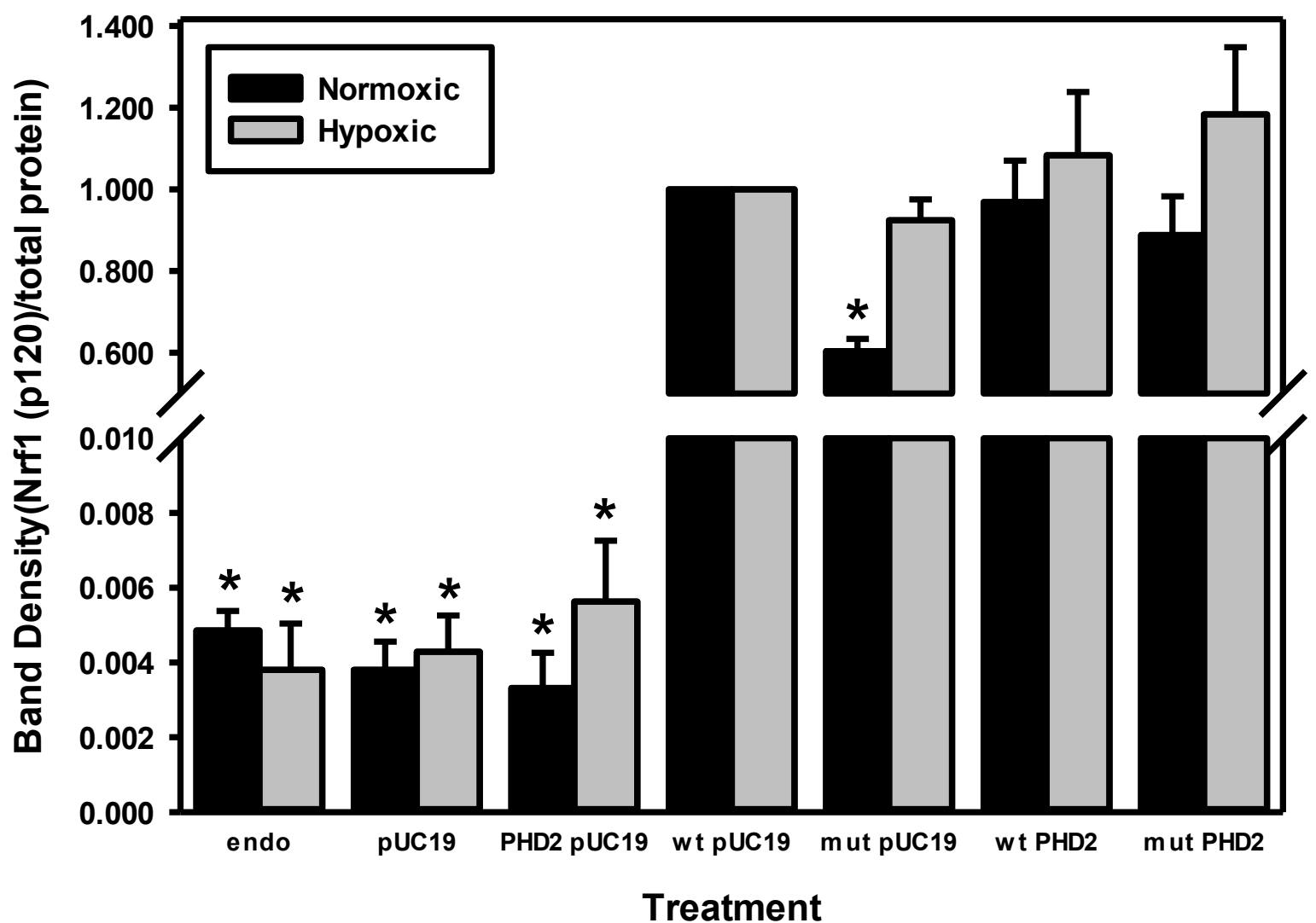


Figure 9: Western blot analysis of Nrf1 protein expression in response to 24 hours of low oxygen (1\%) treatment in comparison to normoxia in transient transfected HEK293T cells.

A predominant band corresponding to the molecular weight of $\mathrm{Nrfl}$ isoform, p120, subjected to 24 hours of hypoxia $\left(1 \% \mathrm{O}_{2}\right)$ treatment in comparison to normoxia $\left(21 \% \mathrm{O}_{2}\right)$ post transient transfection in HEK293T cells (wtNrf1, mutNrf1, wtNrf1/PHD2 or mutNrf1/PHD2 overexpressed). Band density values were normalized to total protein in each lane, as well as to the control signal. (a) Western blot presentation. (b) bar graph from densitometry data analysis. Dunnett's statistical test was performed to compared each of the treatment to control and significant difference were found with samples marked with “*” with a $p<0.05$. 
(a)

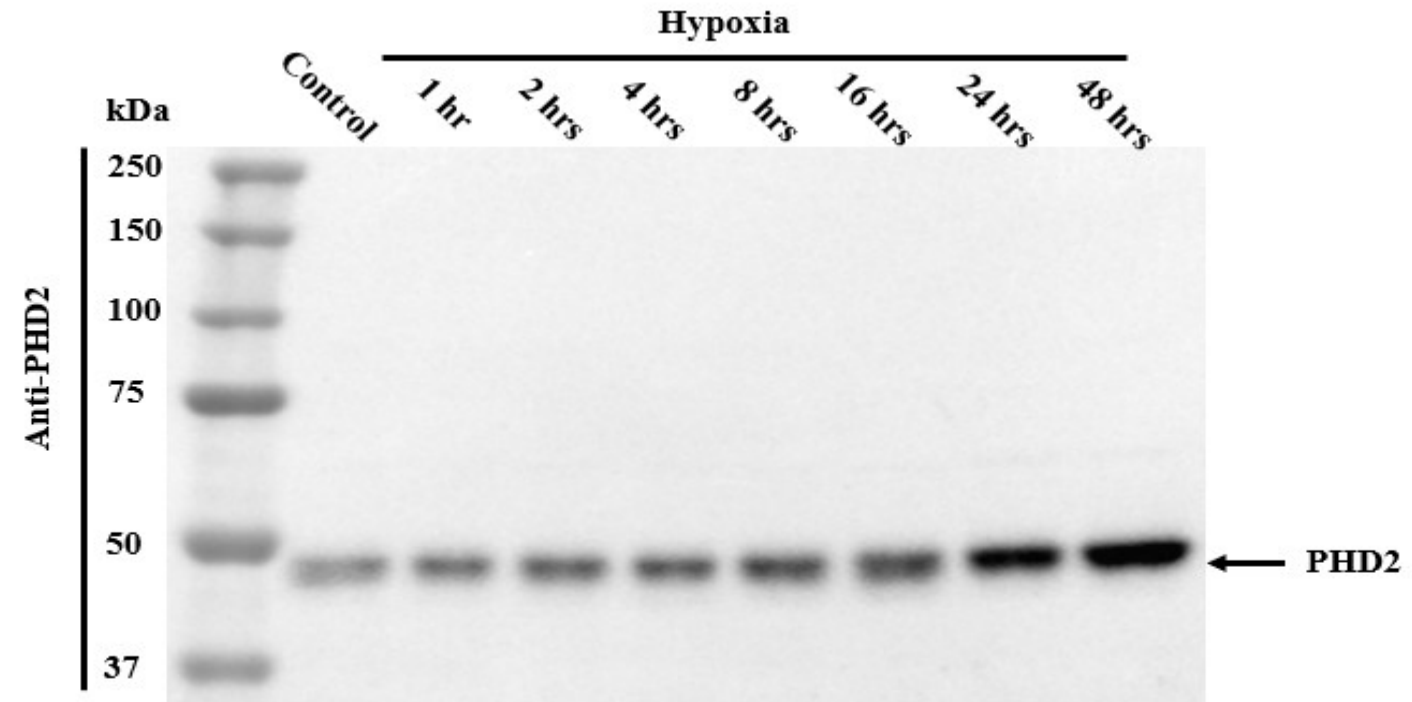

Beta-tubulin

(b)

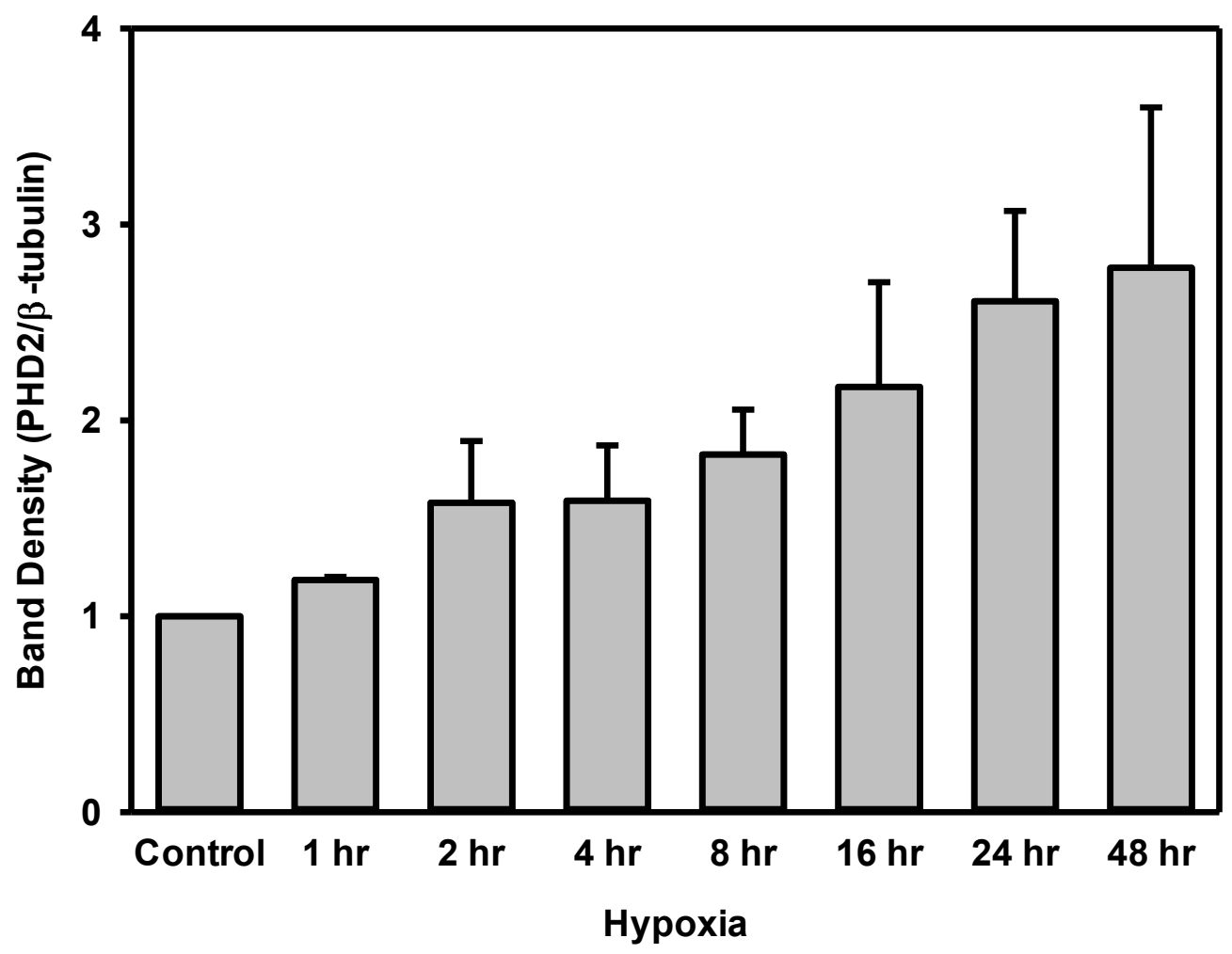


Figure 10: Western blot analysis of endogenous PHD2 protein expression profile in response to various durations of low oxygen (1\%) treatment.

Single band corresponding to the molecular weight of PHD2 (approximately $46 \mathrm{kDa}$ ) during different periods $(0,1,2,4,8,16,24,48$ hours $)$ of hypoxia $\left(1 \% \mathrm{O}_{2}\right)$ treatment in endogenous HEK293T cells. Band density values were normalized to total protein in each lane, as well as to the control signal. (a) Western blot presentation. (b) bar graph from densitometry data analysis. 
(a)

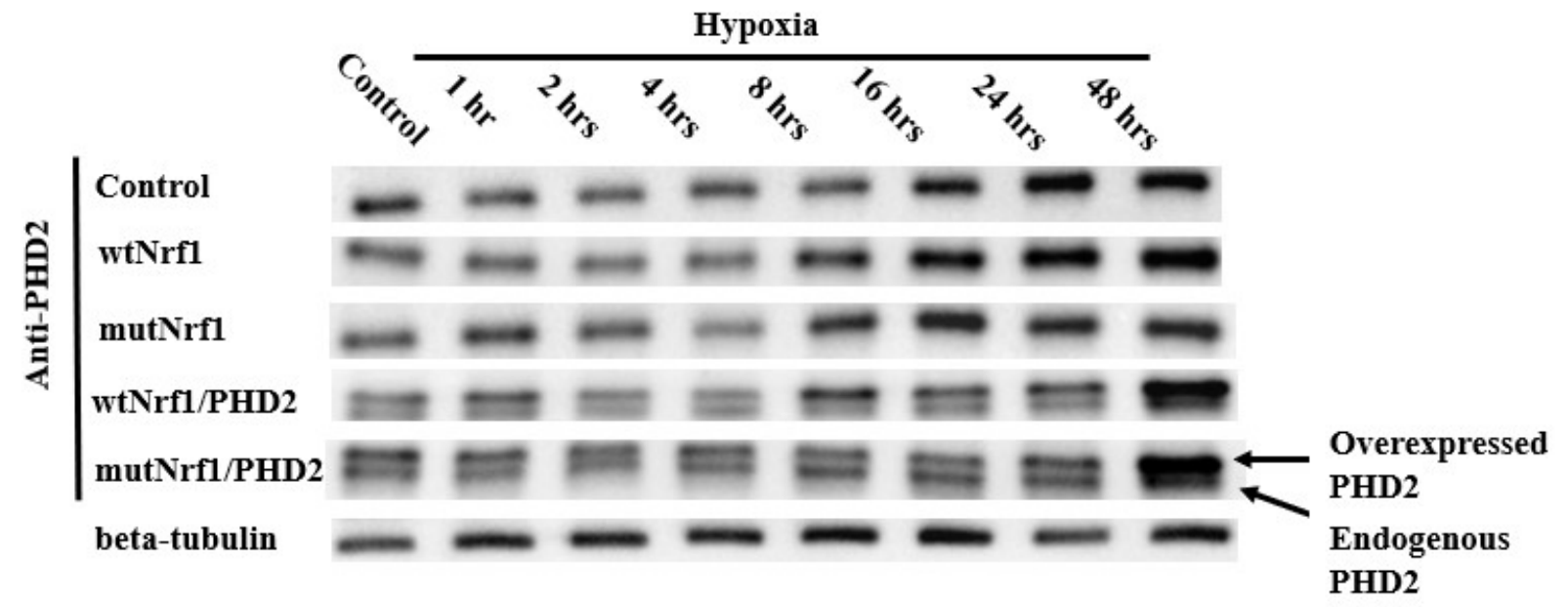

(b)

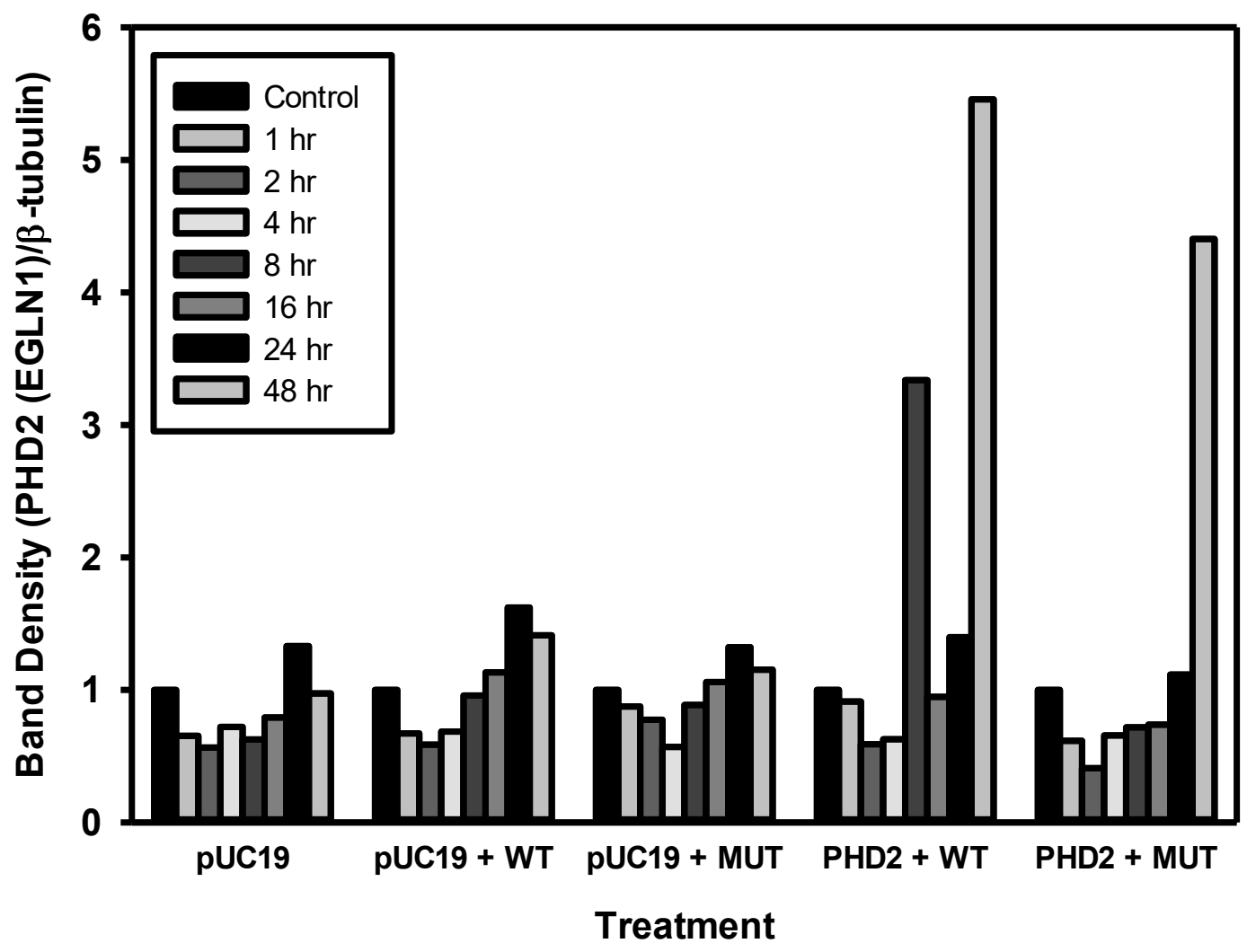


Figure 11: Western blot analysis of PHD2 protein expression in response to various duration of low oxygen (1\%) treatment in transient transfected HEK293T cells.

Single band corresponding to the molecular weight of PHD2 (approximately $46 \mathrm{kDa}$ ) during different period $(0,1,2,4,8,16,24,48$ hours $)$ of hypoxia $\left(1 \% \mathrm{O}_{2}\right)$ treatment in transient transfected HEK293T cells (wtNrf1, mutNrf1, wtNrf1/PHD2 or mutNrf1/PHD2 overexpressed). A second band, with slightly slower electrophoretic shift, was seen in PHD2 overexpressed samples (representing HA-tagged-PHD2). Band density values were normalized to total protein in each lane, as well as to the control signal. (a) Western blot presentation. (b) bar graph from densitometry data analysis. 
(a)

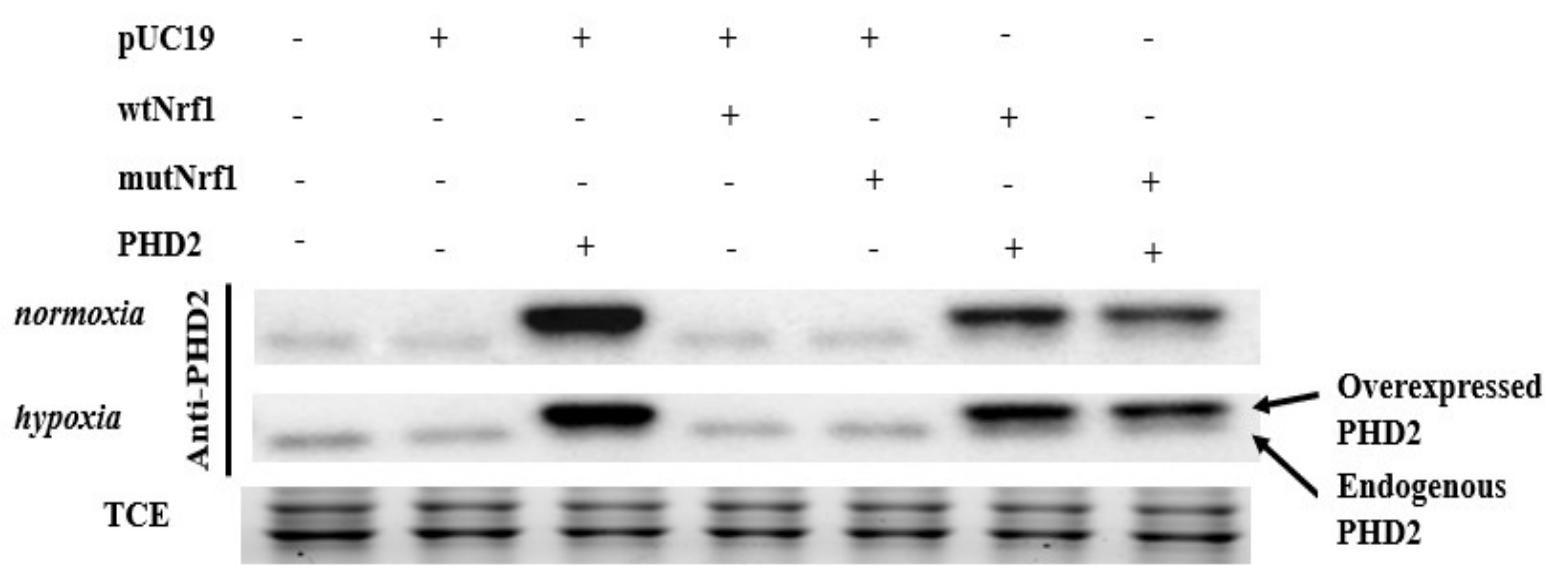

(b)

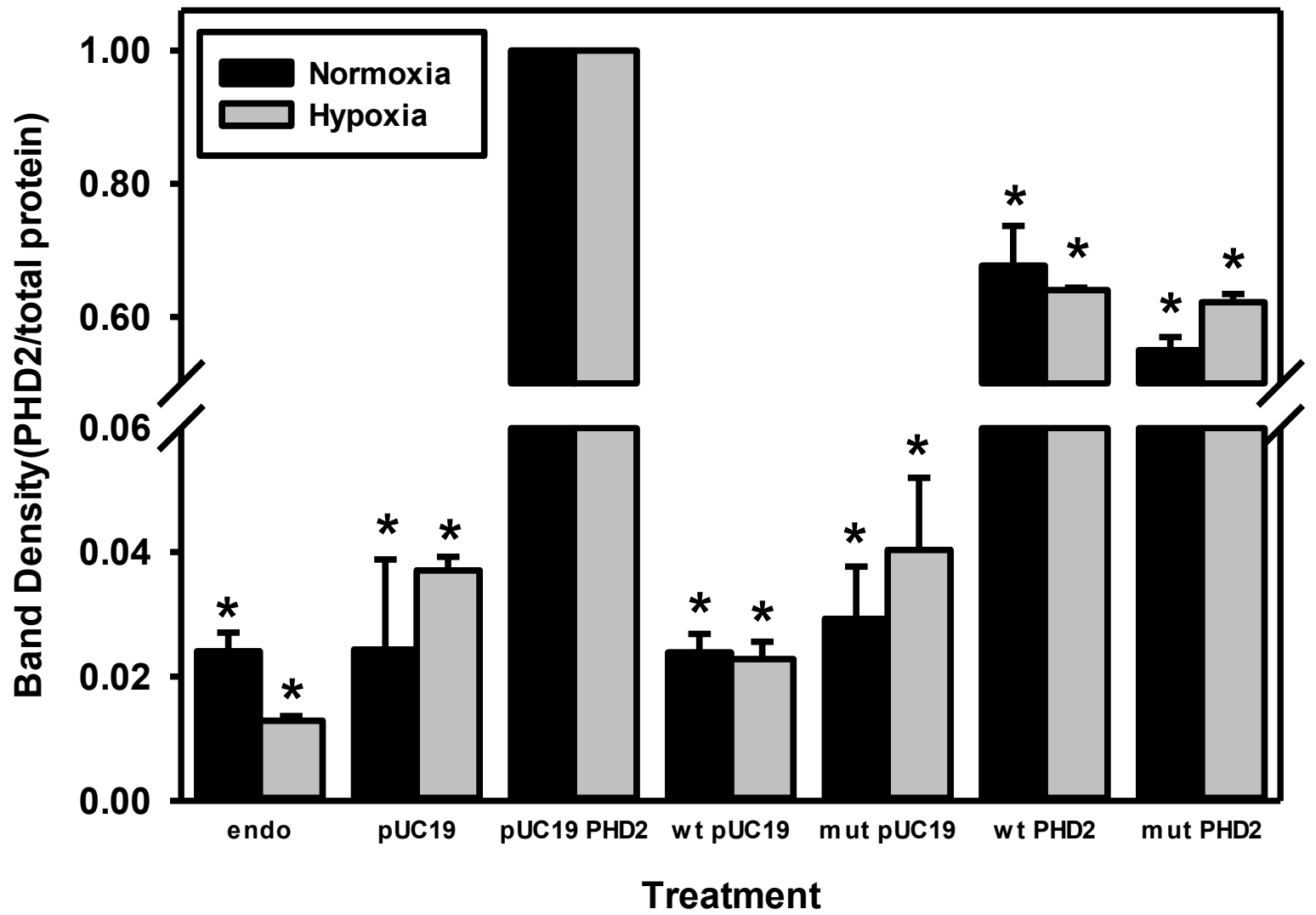


Figure 12: Western blot analysis of PHD2 protein expression in response to 24 hours of low oxygen (1\%) treatment in comparison to normoxia in transient transfected HEK293T cells.

Single band corresponding to the molecular weight of PHD2 (approximately $46 \mathrm{kDa}$ ) subjected to 24 hours of hypoxia $\left(1 \% \mathrm{O}_{2}\right)$ treatment in comparison to normoxia $\left(21 \% \mathrm{O}_{2}\right)$ in transient transfected HEK293T cells (wtNrf1, mutNrf1, wtNrf1/PHD2 or mutNrf1/PHD2 overexpressed). A second band with slightly slower electrophoretic shift seen in PHD2 overexpressed samples was a result of the HA-tag linked in the PHD2 plasmid construct. Band density values were normalized to total protein in each lane, as well as to the control signal. (a) Western blot presentation. (b) bar graph from densitometry data analysis. Dunnett's statistical test was performed to compared each of the treatment to control and significant difference were found with samples marked with "*”" with a $\mathrm{p}<0.05$. 


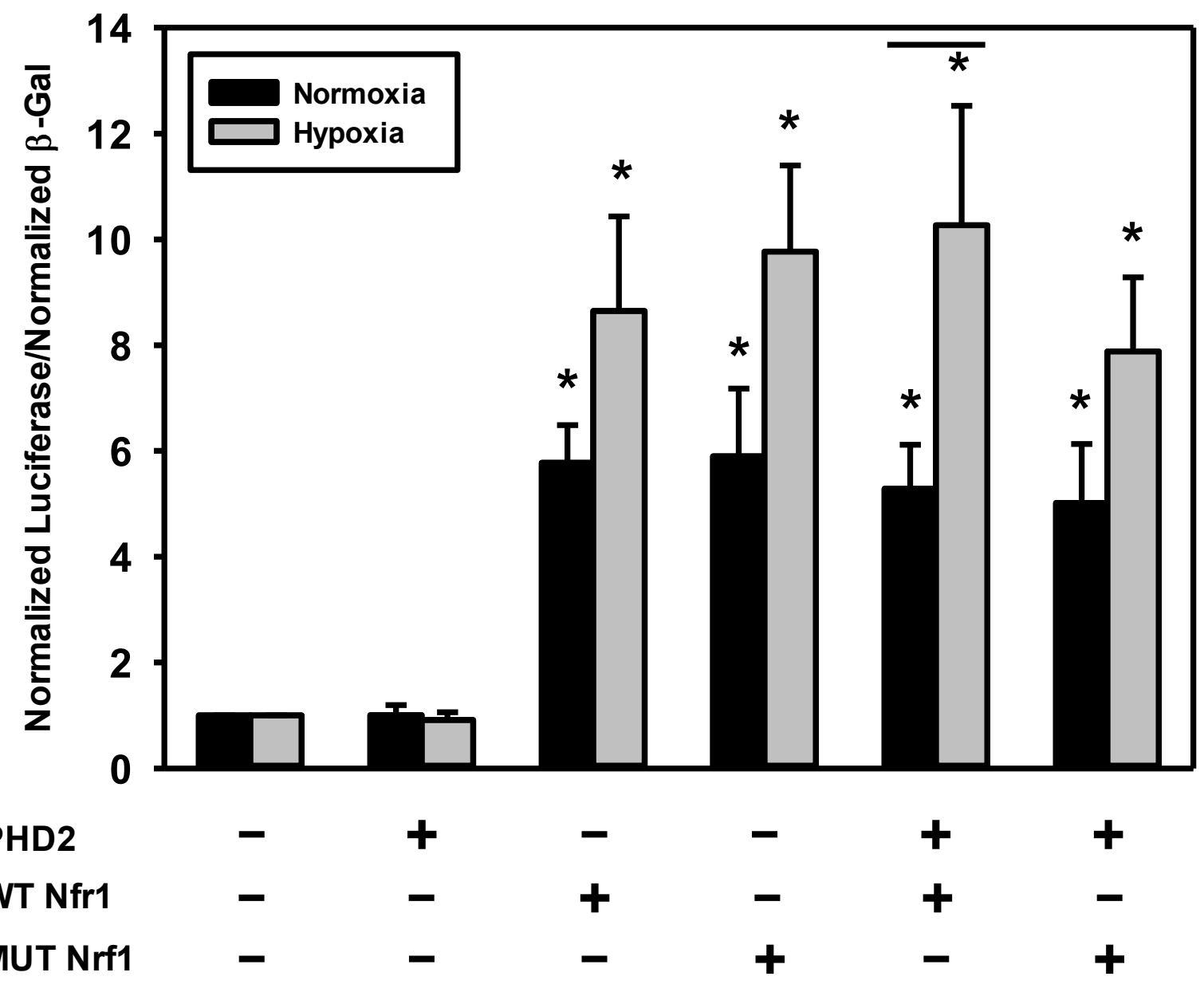


Figure 13: Luciferase reporter assay analysis of Nrf1 transactivation activity in response to 24 hours hypoxia $(1 \% \mathrm{O} 2)$ treatment.

Nrf1 transactivation activity subjected to 24 hours of hypoxia $\left(1 \% \mathrm{O}_{2}\right)$ treatment in comparison to normoxia in transient transfected HEK293T cells (wtNrf1, mutNrf1, wtNrf1/PHD2 or mutNrf1/PHD2 overexpressed). Values shown were normalized to control and luciferase enzymatic activity was normalized to $\beta$-galactosidase. Dunnett's statistical test was performed to compared each of the treatment to control and significant difference were found with samples marked with "*” with a $p<0.05$. 
Table 2: Mass spectrometry analysis for protein samples (endogenous, wtNrf1, mutNrf1, wtNrf1/PHD2 or mutNrf1/PHD2 overexpressed) post co-immunoprecipitation using anti-Nrf1 antibody.

(a) Nrf1 identified in wtNrf1 overexpressed, mutNrf1 overexpressed and mutNrf1/PHD2 coexpressed samples. An E3 ubiquitin-protein ligase Praja-1 identified from endogenous, mutNrf1 overexpressed and mutNrf1/PHD2 co-expressed samples.

\begin{tabular}{|c|c|c|c|c|}
\hline Sample (protein & Nrf1 & Mascot & E3 ubiquitin-protein & Mascot \\
\hline overexpression) & identified & score & ligase Praja-1 identified & score \\
\hline endogenous & No & - & Yes & 37 \\
\hline wtNrf1 & Yes & 108 & No & - \\
\hline mutNrf1 & Yes & 50 & Yes & 55 \\
\hline wtNrf1/PHD2 & No & - & No & - \\
\hline mutNrf1/PHD2 & Yes & 49 & Yes & 43 \\
\hline
\end{tabular}


(b) The complete protein list uncovered from mass spectrometry analysis among all five samples (ion cut-off score 30).

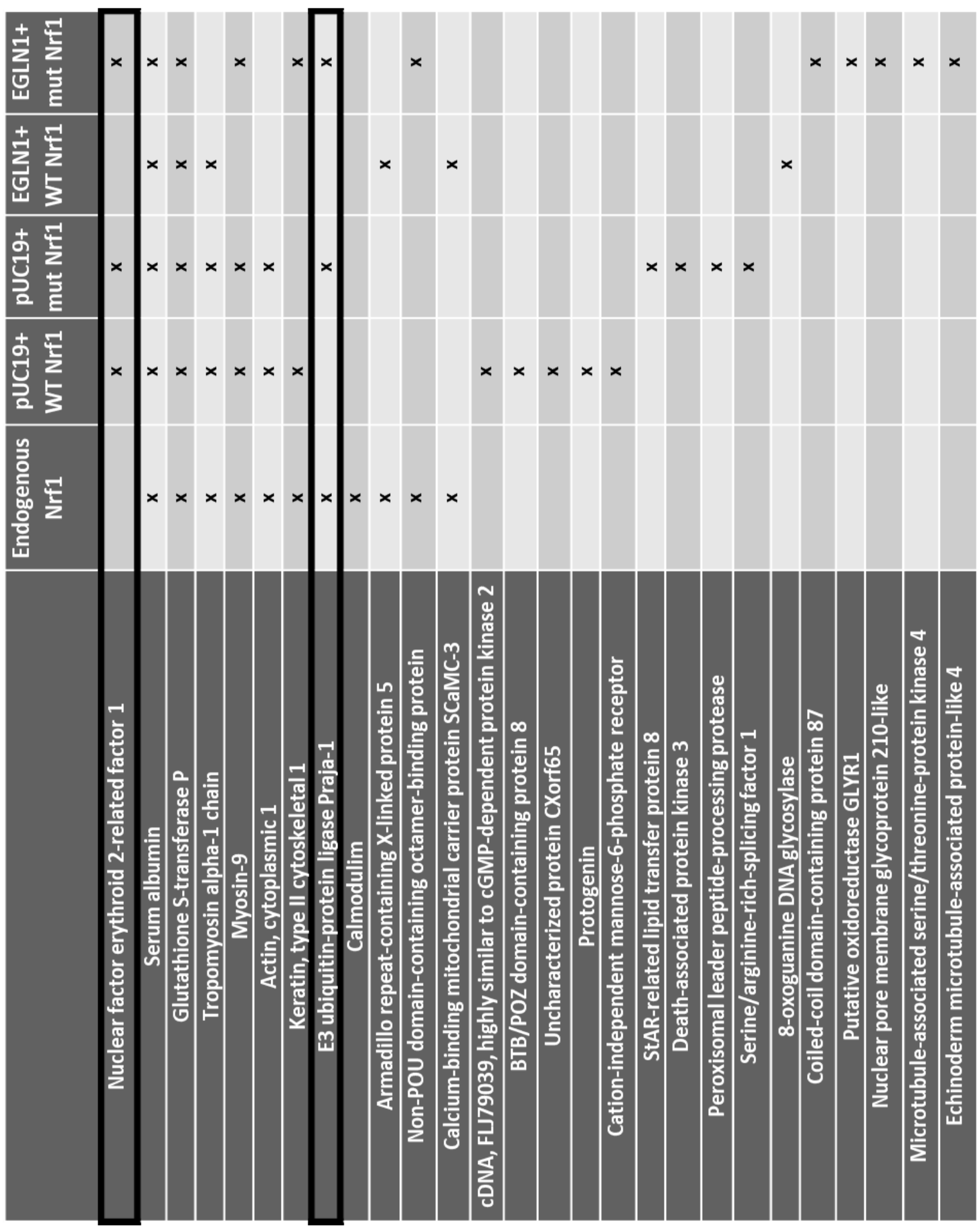




\section{CHAPTER 4: DISCUSSION AND CONCLUSION}

Nrf1 and Nrf2, two transcription factors that belong to the CNC b-ZIP family of proteins have been recognized as important gene regulators involved in antioxidant response and detoxification pathways (Bugno et al., 2015). Many studies have reported genes induced by ROS that were overlapping through Nrf1 and Nrf2 mediated transcriptional regulation; yet there were genes preferrentially regulated in a Nrf1-specific manner, including MT1, MT2, GCLC, GCLM, GSS and number of proteasome subunit genes (Radhakrishnan et al., 2010, Steffen, et al., 2010). It has been shown that Nrf2 is negatively regulated by a cystine rich protein called Keap1, which serves as a ROS sensor (Saito et al., 2016). The interaction between Nrf2 and reduced Keap1 leads to the ubiquitination and degradation of Nrf2, whereas oxidized Keap1 disassociates from Nrf2 enabling it to travel to the nucleus and activate transcription (Kobayashi et al., 2004; Furukawa et al., 2005). Unlike Nrf2, the endoplasmic reticulum (ER) subcellular localization of Nrf1, and many functional truncated isoforms generated from Nrfl, add layers of complexity in the understanding of Nrf1-mediated gene regulation (Zhang et al., 2007; Wang and Chen, 2006). Recent studies have proposed possible mechanisms in the release of active Nrf1 from its inactive, ER membrane-bound form. Tsuchiya et al. has reported that Nrf1 was ubiquitously degraded in a $\beta$-TrCP- (in the nucleus) and Hrd1- (in the cytoplasm) dependent manner (Tsuchiya et al., 2011) under normal conditions. The proteolytic cleavage of Nrf1 after Leu-104 by aspartyl protease DNA-damage inducible 1 homolog 2 (DDI2) was found critical to yield active Nrf1. This directly affects the production of subunits of the proteasome (Sha and Goldberg, 2014, Koizumi et al., 2016, Sha and Goldberg, 2016), as well as antioxidant and detoxification enzymes. However, the removal of DDI2 from the cells did not completely prevent the production of proteolytic forms of Nrfl, as suggested by Koizumi et al. (Koizumi et al. 2016), which indicated that there were other potential enzymatic 
modifications on Nrf1 that contributed to the regulation of Nrf1 activity. Our study was meant to examine the effect on Nrfl expression and function by possible hydroxylation modification on Nrf1 through PHD2, in response to oxidative stress.

\subsection{Oxygen has an effect on Nrf1 expression and PHD2 hydroxylation may not directly lead to proteasomal processing of Nrf1}

Endogenous Nrf1 expression during hypoxia time-course treatment [Figure 7] has shown a steady shift towards the stabilization of the deglycosylated active isoform of Nrf1 (p95) and the destabilization of the glycosylated inactive isoform (p120). Hypoxic conditions directly contribute to elevated subcellular ROS which, in turn, mediates the cellular antioxidant response through the binding of Nrf1 to ARE sequences (Chepelev et al. 2011). The membrane-bound p120 form is then retrotranslocated through the ER membrane and deglycosylated, where it is further processed to give rise to the multiple truncated forms of Nrfl, which enter the nucleus and bind to AREs, acting as negative regulators of the antioxidant and detoxification gene response (Bugno et al., 2015). During the hypoxia time-course treatment, expression of the active $\mathrm{p} 85$ isoform peaked at 1 hour of hypoxia treatment, which indicated a short response time for Nrf1 production after the generation of ROS. After transient transfection of cells with different plasmids (wtNrf1, mutNrfl, wtNrf1/PHD2, mutNrf1/PHD2), the same hypoxia time-course treatment did not yield similar trends in results as with endogenous (non-transfected) cells [Figure 8]. p120 was shown to be the most predominant isoform and the overexpression of Nrfl did not increase the production of other shorter isoforms. The accumulation of p120 was more significant when wtNrf1 was co-expressed with PHD2, which indicated that PHD2 had a stabilizing effect on p120 when there was lack of 
oxygen, and the potential hydroxylation site in Nrf1 (proline 398) was required for this process. As a result, shorter (truncated) forms of Nrf1 were not seen when p120 was overexpressed.

Co-expression of Nrf1 and PHD2 (EGLN1) in cells subjected to 24 hours of hypoxia showed no statistical significant difference in protein stability between Nrf1 and Nrf1/PHD2 overexpressed samples [Figure 9]. However, the p120 form of Nrf1 was relatively more stable, under hypoxia, when co-expressed with PHD2. Although only subtle changes were observed, this again indicated that hydroxylation may play an important role in Nrfl stability. Since the coexpression of wtNrf1/PHD2 and mutNrf1/PHD2 appeared to maintained similar p120 protein levels, this can potentially due to the presence of alternative proline residues that can be recognized by PHD2 as substrate, thereby the hydroxylation on other proline residues in Nrf1 by PHD2/EGLN1 may be possible.

\subsection{PHD2 is hypoxia inducible}

Hypoxia treatment in both endogenous [Figure 10] and transiently transfected [Figures 11 and 12] cells showed the stabilization of PHD2 and its accumulation over the time course of hypoxia exposure. Our results corresponded to the Berra's study that showed that PHD2 was upregulated when cells were treated with $\mathrm{CoCl}_{2}$, a hypoxia mimetic (Epstein et al., 2001, Berra, et al., 2003). The fact that $\mathrm{O}_{2}$ is one of the main substrates for PHD2 activity (Epstein et al., 2001, Lieb et al., 2002), PHD2 may regulate itself as an adaptive response of the cells to low oxygen. The expression of PHD2 was also reported to be regulated by the ubiquitin-proteasome pathway (Lieb et al., 2002; Cioffi et al., 2003), which may indicate that the expression of PHD2 is indirectly regulated by Nrf1 activity. As a result of accumulation of p120 Nrfl during the transient transfection and overexpression of Nrf1 in cells, endogenous active Nrf1 levels declined, which 
induced an impaired expression of proteasome proteins. This, in turn, likely slowed down the ubiquitous degradation of PHD2. In addition, Coiffi et al. showed that the mRNA levels of PHD2 were not responsive to hypoxia treatment (both $\mathrm{CoCl}_{2}$ and a gradual decrease in $\mathrm{O}_{2}$ levels), which also suggests that PHD2 is regulated at a post-transcriptional or post-translational level by oxygen. Interestingly, we found that when PHD2 was not co-expressed with Nrf1, endogenous PHD2 was relatively more stable, which may be due to rapid proteasomal degradation of endogenous Nrfl, resulting in weaker transactivation activity of the genes for proteasome subunits.

\subsection{Hypoxia stabilize the transactivation activity of Nrf1}

It was found that the transactivation activity of Nrf1 was higher under hypoxic conditions, in comparison to normal oxygen conditions, when an ARE-luciferase reporter was used [Figure 12]. As it was proposed in other studies, release from the ER membrane and entry into the nucleus is a prerequisite for Nrf1-controlled gene expression (Bugno et al., 2015; Zhang and Xiang, 2016). In our analysis, the ARE contained in the pGL3.47 luciferase gene construct served as the direct target DNA binding sequence for Nrf1 (as opposed to Nrf2), therefore, the increased luciferase enzymatic activity was directly proportional to Nrf1 transactivation activity. This result indicated Nrf1 activity was induced by hypoxia treatment; possibly by ROS produced under hypoxic conditions (Lee et al., 2018). However, results from luciferase assays did not show significant differences in Nrf1 transactivation activity between wtNrf1 or mutNrf1 co-expressed with PHD2. This implies that PHD2 did not play a direct regulatory role in stabilizing Nrf1 activity. However, results on endogenous and overexpressed Nrf1 alone show that oxygen levels had impact in Nrf1 function. 


\subsection{Hydroxylation through PHD2 may be transient and is indirectly involved in ubiquitination of Nrf1}

Co-immunoprecipitation studies utilizing overexpressed Nrf1, followed by mass spectrometry analysis, has revealed a list of proteins that may associate with Nrf1 under different conditions [Table 2 (b)]. Nrfl was identified in all Nrfl overexpressed and co-immunoprecipitated samples except for the wtNrf1/PHD2 co-expressed sample, which did not align with the results found in Western Blot analysis [Figure 8 and 9]. The results from mass spectrometry are still preliminary and required replicates to draw confirmatory conclusions. There were no peptide fragments found matching PHD2, which indicated that the interaction between Nrf1 and PHD2 were highly transient if the hydroxylation on the Nrfl proline indeed occur. Interestingly, the ringtype E3 ubiquitin-protein ligase Praja-1 was only identified in mutNrf1 transfected samples [Table 2 (a)]. Praja-1 was previously found to interact with FBXW7, a F-box protein composed of one of the four subunits of ubiquitin protein ligase complex called SCFs (SKP1-cullin-F-Box) (Steffen et al., 2010). In this study, $\beta-\operatorname{TrCP}$, an adaptor for the SCF (Skp1-Cul1-F-box protein) ubiquitin ligase, was required in Nrf1 ubiquitous proteasomal degradation (Tsuchiya et al., 2011). According to these findings, mass spectrometry results suggested that the mutation on the potential hydroxylation residue on Nrfl had increased the accessibility of interacting proteins, such as ringtype E3 ubiquitin ligases, to interact with potential targets for polyubiquitination. Proline hydroxylation of Nrfl may alter the protein in a way that subsequent ubiquitination cannot take place, thereby stabilizing the protein. Surprisingly, there was no small Maf proteins found in any of these samples. These proteins form heterodimers with Nrfl to assist DNA binding and transactivation activities (Blank, 2008; Kanna et al., 2012). The expression of small Maf proteins are also controlled by the ubiquitin-proteasomal pathway (Mao et al., 2007). It is possible that the 
accumulation of inactive, glycosylated p120 Nrf1, and the decline of active, deglycosylated Nrf1, had a negative net effect on dimerization to Maf proteins. The overexpression of Nrfl may have accelerated its degradation.

In conclusion, we found that oxygen had an effect on Nrfl protein levels and activity and this effect may not be directly through PHD2 hydroxylation. The expression of Nrf1, as shown by Western blotting, may not have shown the complete Nrfl protein profile. As well as proteolytic processing of Nrf1, which produces multiple Nrf1 isoforms, different type of post-translational modifications of Nrfl may produce even more variants in Nrf1, which may interfere and mask the actual effect of hypoxia in Nrfl stability. We were able to show the stabilization of endogenous Nrf1 protein and function upon on hypoxia treatment. PHD2 overexpression did not show any significant effects on either Nrf1 protein expression or transactivation activity. Additional studies may focus on the role of another proline residue present in the Nrf1 LXXLAP sequence (LLPLAP). Further tests may also utilize an in-solution luminescent hydroxylation assay developed to assay for PHD2/EGLN1 activity. Mass spectrometry analysis can be further extended by using reversible cross-linking reagents, such as dithiobis[succinimidylpropionate] (DSP), which will allow antiNrf1 antibodies to capture transient protein-protein interactions. 


\section{REFERENCES}

Amber, B. J. and Michelle, C. B. (2007). Hypoxia-induced and stress-specific changes in chromatin structure and function. Mut. Res. 618: 149-162.

Annalisa, M. V. (2015). Hypoxia induces mitochondrial protein misfolding. Sci. Signal. 8(391): 239.

Berra, E., Benizri, E., Ginouvès, A., Volmat, V., Roux, D., and Pouysségur, J. (2003). HIF prolylhydroxylase 2 is the key oxygen sensor setting low steady-state levels of HIF-1alpha in normoxia. EMBO J. 22(16): 4082-4090.

Blank, V. (2008). Small Maf proteins in mammalian gene control: mere dimerization partners or dynamic transcriptional regulators? J. Mol. Biol. 376: 913-925.

Brostrom, C. O. and Brostrom, M. A. (1998). Regulation of translational initiation during cellular responses to stress. Prog. Nucleic Acid Res. Mol. Biol. 58: 79-125.

Buchman, T. G. (2002). The community of the self. Nature. 420: 246-251.

Bugno, M., Daniel, M., Chepelev, N. L. and William G. Willmore. (2015). Changing gears in Nrf1 research, from mechanisms of regulation to its role in disease and prevention. Biochem. Biophys. Acta (BBA) - Gene Regulatory Mechanisms. 1849(10): 1260-1276.

Cao, S. S., Kaufman, R. J. (2012). Unfolded protein response. Curr. Biol. 22: 622-626.

Chan, J. Y., Kwong, M., Lu, R., Chang, J., Wang, B., Yen, T. S. and Kan, Y. W. (1998). Targeted disruption of the ubiquitous CNC-bZIP transcription factor, Nrf-1, results in anemia and embryonic lethality in mice. EMBO J. 17: 1779-1787. 
Chan, K., Lu, R., Chang, J. C. and Kan, Y. W. (1996). NRF2, a member of the NFE2 family of transcription factors, is not essential for murine erythropoiesis, growth, and development. Proc. Natl. Acad. Sci. 93: 13943-13948.

Cioffi, C. L., Liu, X. Q., Kosinski, P. A., Garay, M., Bowen, B. R. (2003). Differential regulation of HIF-1 alpha prolyl-4-hydroxylase genes by hypoxia in human cardiovascular cells. Biochem. Biophys. Res. Commun. 303(3): 947-53.

Coimbra-Costa, D., Alva, N., Duran, M., Carbonell, T., and Rama, R. (2017). Oxidative stress and apoptosis after acute respiratory hypoxia and reoxygenation in rat brain. Red. Biol. 12: 216225.

Dhakshinamoorthy, S., Jain, A. K., Bloom, D. A. and Jaiswal, A. K. (2005). Bach1 competes with Nrf2 leading to negative regulation of the antioxidant response element (ARE)-mediated NAD(P)H:quinone oxidoreductase 1 gene expression and induction in response to antioxidants. J. Biol. Chem. 280: 16891-16900.

Dröge, W. (2002). Free radicals in the physiological control of cell function. Physiol. 82(1): 4795.

Eizirik, D. L. and Mandrup-Poulsen, T. (2001). A choice of death - the signal-transduction of immune-mediated beta-cell apoptosis. Diabetologia. 44(12): 2115-2133.

Ella, E., George H. G., Guichun W., Jose R. P. and Heung M. L. (1999). Hypoxia-induced mitochondrial and nuclear DNA damage in the rat brain. J. Neurosci. Res. 58: 262-269.

Epstein, A. C., Gleadle, J. M., McNeill, L. A., Hewitson, K. S., O'Rourke, J., Mole, D. R., Mukherji, M., Metzen, E., Wilson, M.I., Dhanda, A., Tian, Y.M., Masson, N., Hamilton, D.L., Jaakkola, 
P., Barstead, R., Hodgkin, J., Maxwell, P.H., Pugh, C.W., Schofield, C.J. and Ratcliffe, P.J. (2001). C. elegans EGL-9 and mammalian homologs define a family of dioxygenases that regulate HIF by prolyl hydroxylation. Cell. 107(1): 43-54.

Farrer, B. T. and Pecoraro, V. L. (2002). Heavy-metal complexation by de novo peptide design. Curr. Opin. Drug Discov. Dev. 5: 937-943.

Ferrara, N. (1999). Molecular and biological properties of vascular endothelial growth factor. $J$. Mol. Med. 77: 527-543.

Ferrara, N. and Davis-Smyth, T. (1997). The biology of vascular endothelial growth factor. Endocr. Rev. 18: 4-25.

Forsythe, J. A., Jiang, B. H., Iyer, N. V., Agani, F., Leung, S. W., Koos, R. D. and Semenza, G. L. (1996). Activation of Vascular Endothelial Growth Factor Gene Transcription by HypoxiaInducible Factor 1. Mol. and Cel. Biol. 16: 4604-4613.

Furukawa, M. and Xiong, Y. (2005). BTB protein Keap1 targets antioxidant transcription factor Nrf2 for ubiquitination by the Cullin 3-Roc1 ligase. Mol. Cell Biol. 25: 162-171.

Gornicka, A., Morris-Stiff, G., Thapaliya, S., Papouchado, B. G., Berk, M., and Feldstein, A. E. (2011). Transcriptional profile of genes involved in oxidative stress and antioxidant defense in a dietary murine model of steatohepatitis. ARS. 15(2): 437-445.

Gradin, K., Takasaki, C., Fujii-Kuriyama, Y. and Sogawa, K. (2002). The transcriptional activation function of the HIF-like factor requires phosphorylation at a conserved threonine. J. Biol. Chem. 277(26): 23508-23514.

Guzik, T. J. and Harrison, D. G. (2006). Vascular NADPH oxidases as drug targets for novel antioxidant strategies. Drug Discov. Today. 11: 524-533. 
Harsdorf, R., Li, P. F. and Dietz, R. (1999). Signaling pathways in reactive oxygen species-induced cardiomyocyte apoptosis. Circul. 99(22): 2934-2941.

Hay, N. and Sonenberg, N. (2004). Upstream and downstream of mTOR. Gene. \& Dvlp. 18(16): $1926-45$.

Huang, D., Li, T., Li, X., Zhang, L., Sun, L., He, X., Zhong, X., Jia, D., Song, L., Semenza, G. L., Gao, P. and Zhang, H. (2014). HIF-1-mediated suppression of acyl-CoA dehydrogenases and fatty acid oxidation is critical for cancer progression. Cell Rep. 8: 1930-42.

Huang, J., Zhao, Q., Mooney, S. M., and Lee, F. S. (2002). Sequence determinants in hypoxiainducible factor-1alpha for hydroxylation by the prolyl hydroxylases PHD1, PHD2, and PHD3. J. Biol. Chem. 277(42): 39792-39800.

Itoh, K., Chiba, T., Takahashi, S., Ishii, T., Igarashi, K., Katoh, Y., Oyake, T., Hayashi, N., Satoh, K., Hatayama, I., Yamamoto, M. and Nabeshima Y. (1997). An Nrf2/small Maf heterodimer mediates the induction of phase II detoxifying enzyme genes through antioxidant response elements, Biochem. Biophys. Res. Commun. 236: 313-322.

Jeong, J. W., Bae, M. K., Ahn, M. Y., Kim, S. H., Sohn, T. K., Bae, M. H., Yoo, M. A., Song, E. J., Lee, K. J. and Kim, K. W. (2002). Regulation and destabilization of HIF-1alpha by ARD1-mediated acetylation. Cell. 111(5): 709-720.

Kannan, M. B, Solovieva, V. and Blank, V. (2012). The small MAF transcription factors MAFF, MAFG and MAFK: current knowledge and perspectives. BBA-Mol. Cell Res. 1823(10): 1841-1846. 
Kasprzak, K. S. (2002). Oxidative DNA and protein damage in metal-induced toxicity and carcinogenesis. Free Radic. Biol. Med. 32: 958-967.

Kempner, E. S. (1993). Damage to proteins due to the direct action of ionizing radiation. Q. Rev. Biophys. 26:27-48.

Kharroubi, I., Ladriere, L. Cardozo, A. K., Dogusan, Z., Cnop, M. and Eizirik, D. L. (2004). Free fatty acids and cytokines induce pancreatic $\beta$-cell apoptosis by different mechanisms: role of nuclear factor-kB and endoplasmic reticulum stress. Endocrin. 145(11): 5087-5096.

Kim, D. H., Sarbassov, D. D., Ali, S. M., King, J. E., Latek, R. R., Erdjument-Bromage, H., Tempst, P. and Sabatini DM (2002). mTOR interacts with raptor to form a nutrient-sensitive complex that signals to the cell growth machinery. Cell. 110(2): 163-75.

Kobayashi, A., Kang, M. I., Okawa, H., Ohtsuji, M., Zenke, Y., Chiba, T., Igarashi, K. andYamamoto,M. (2004). Oxidative stress sensor Keap1 functions as an adaptor for Cul3based E3 ligase to regulate proteasomal degradation of Nrf2. Mol. Cell Biol. 24: 7130-7139.

Kobayashi, A., Ohta, T. and Yamamoto, M. (2004) Unique function of the Nrf2-Keap1 pathway in the inducible expression of antioxidant and detoxifying enzymes. Methods Enzymol. 378: 273-286.

Koizumi, S., Irie, T., Hirayama, S., Sakurai, Y., Yashiroda, H., Naguro, I. and Murata, S. (2016). The aspartyl protease DDI2 activates Nrfl to compensate for proteasome dysfunction. eLife, 5: e18357. 
Lee, C. S., Ho, D. V. and Chan, J. Y. (2013). Nuclear factor-erythroid 2-related factor 1 regulates expression of proteasome genes in hepatocytes and protects against endoplasmic reticulum stress and steatosis in mice. FEBS J. 280: 3609-3620.

Lee, C. S., Lee, C., Hu, T., Nguyen, J. M., Zhang, J., Martin M. V., Vawter, M. P., Huang, E. J. and Chan, J. Y. (2011). Loss of nuclear factor E2-related factor 1 in the brain leads to dysregulation of proteasome gene expression and neurodegeneration. Proc. Natl. Acad. Sci. 108: $8408-8413$.

Lee, E., Kim, G. H., and Yoon, G. (2018). Mitochondrial ROS regulates hepatoma cell invasiveness via NFE2L1. Free Radical Biol. and Med. 120: S140.

Lieb, M. E., Menzies, K., Moschella, M. C., Ni, R. and Taubman, M. B. (2002). Mammalian EGLN genes have distinct patterns of mRNA expression and regulation. Biochem. Cell Biol. 80(4): 421-426.

Lisy, K., Peet, D.J. (2008). Turn me on: regulating HIF transcriptional activity. Cell Death Differ. 15: $642-649$.

Mahon, P. C., Hirota, K., and Semenza, G. L. (2001). FIH-1: a novel protein that interacts with HIF-1 alpha and VHL to mediate repression of HIF-1 transcriptional activity. Genes $\& d v l p$. 15(20): 2675-2686.

Mao, X., Stewart, A. K., Hurren, R., Datti, A., Zhu, X., Zhu, Y., Shi, C., Lee, K., Tiedemann, R., Eberhard, Y., Trudel, S., Liang, S., Corey, S. J., Gillis, L. C., Barber, D. L., Wrana, J. L., Ezzat, S., and Schimmer, A. D. (2007). A chemical biology screen identifies glucocorticoids that regulate c-maf expression by increasing its proteasomal degradation through upregulation of ubiquitin. Blood. 110(12): 4047-4054. 
Masson, N., William, C., Maxwell, P. H., Pugh, C. W. and Racliffe, P. J. (2001). Independent function of two destruction domains in hypoxia-inducible factor-alpha chains activated by prolyl hydroxylation. EMBO J. 20: 5197-5206.

McMahon, M , Itoh, K., Yamamoto, M., Chanas, S. A., Henderson, C. J., McLellan, L. I., Wolf, C. R., Cavin, C. and Hayes, J. D. (2001). The Cap'n'Collar basic leucine zipper transcription factor Nrf2 (NF-E2 p45-related factor 2) controls both constitutive and inducible expression of intestinal detoxification and glutathione biosynthetic enzymes. Canc. Res. 61: 3299-3307.

McMurray, J., McLay, J., Chopra, M., Bridges, A. and Belch. J. J. F. (1999). Evidence for enhanced free radical activity in chronic congestive heart failure secondary to coronary artery disease. American Journal of Cardiology. 65(18): 1261-1262.

Niecknig, H., Tug, S., Reyes, B. D., Kirsch, M., Fandrey, J. and Berchner-Pfannschmidt, U. (2012). Role of reactive oxygen species in regulation of HIF-1 by prolyl hydroxylase 2 under mild hypoxia. Free Radical Res. 46(6): 705-717.

Oh, D. H., Rigas, D., Cho, A. and Chan, J. Y. (2012). Deficiency in the nuclear-related factor erythroid 2 transcription factor (Nrf1) leads to genetic instability. FEBS J. 279: 4121-4130.

Ohtsubo, T., Kamada, S., Mikami, T., Murakami, H. and Tsujimoto Y. (1999). Identification of NRF2, a member of the NF-E2 family of transcription factors, as a substrate for caspase-3(like) proteases. Cell Death Differ. 6: 865-872.

Ohtsuji, M., Katsuoka, F., Kobayashi, A., Aburatani, H. Hayes, J. D. and Yamamoto, M. (2008). Nrf1 and Nrf2 play distinct roles in activation of antioxidant response element-dependent genes. J. Biol. Chem. 283(48): 33554-33562. 
Pandey, K. B. and Rizvi, S. I. (2010). Markers of oxidative stress in erythrocytes and plasma during aging in humans. Oxid. Med. Cell Longev. 3(1): 2-12.

Potters, G., Horemans, N. and Jansen, M. (2010). The cellular redox state in plant stress biology A charging concept. Plant Physio. Biochem. 48(5): 292-300.

Rabinowitz, M. H. (2013). Inhibition of hypoxia-inducible factor prolyl hydroxylase domain oxygen sensors: tricking the body into mounting orchestrated survival and repair response. J. Med. Chem. 56(23): 9369-9402.

Radhakrishnan, S. K., den Besten, W. and Deshaies, R. J. (2014). p97-dependent retrotranslocation and proteolytic processing govern formation of active Nrfl upon proteasome inhibition. Elife. 3: $\mathrm{e} 01856$.

Radhakrishnan, S. K., Lee, C. S., Young, P., Beskow, A., Chan, J. Y. and Deshaies, R.J. (2010). Transcription factor Nrf1 mediates the proteasome recovery pathway after proteasome inhibition in mammalian cells. Mol. Cell. 38: 17-28.

Radi, R. (2013). Peroxynitrite, a stealthy biological oxidant. J. Biol. Chem. 288(37): 26464-26472.

Raj, C. and Ruslan, M. (2014). Stress, inflammation, and defense of homeostasis. Mol. Cell. 54(2): 281-288.

Reddy, S. P. (2008). The antioxidant response element and oxidative stress modifiers in airway diseases. Curr. Mol. Med., 8(5): 376-383.

Reinhardt, H. C., Schumacher, B. (2012). The p53 network: cellular and systemic DNA damage responses in aging and cancer. Trends Genet. 28:128-136. 
Richard, I. M. (2008). Proteotoxic stress and inducible chaperone networks in neurodegenerative disease and aging. Genes Dev. 22(11): 1427-1438.

Saito, R., Suzuki, T., Hiramoto, K., Asami, S., Naganuma, E., Suda, H., Iso, T., Yamamoto H., Morita M., Baird L., Furusawa Y., Negishi T., Ichinose M. and Yamamoto, M. (2016). Characterizations of Three Major Cysteine Sensors of Keap1 in Stress Response. Mol. and cell biol. 36(2): 271-284.

Sekhar, P. R. (2008). The antioxidant response element and oxidative stress modifiers in airway diseases. Curr. Mol. Med. 8(5): 376-383.

Semenza, G. L. (2011). Oxygen sensing, homeostasis, and disease. N Engl. J. Med. 365: 537-547.

Sha, Z. and Goldberg, A. L. (2014). Proteasome-mediated processing of Nrf1 is essential for coordinate induction of all proteasome subunits and p97. Curr. Biol. 24: 1573-1583.

Sha, Z., and Goldberg, A. L. (2016). Reply to Vangala et al.: Complete inhibition of the proteasome reduces new proteasome production by causing Nrf1 aggregation. Curr. Biol. 26(18): R836R837.

Simone, F., Adrienne M. G., Osamu H. and Afshin S. (2009). Cellular stress responses: cell survival and cell death. Int. J. of Cell Biol. 2010: 23.

Steffen, J., Seeger, M., Koch, A. and Krüger, E. (2010). Proteasomal degradation is transcriptionally controlled by TCF11 via ERAD-dependent feedback loop. Mol. Cell. 40(1): $147-15$.

Tang, X., Luo, Y. X., Chen, H. Z. and Liu, D. P. (2014). Mitochondria, endothelial cell function, and vascular diseases. Front. Physiol. 5: 175. 
Tsuchiya, Y., Morita, T., Kim, M., Iemura, S., Natsume, T., Yamamoto, M., and Kobayashi, A. (2011). Dual regulation of the transcriptional activity of Nrf1 by $\beta$-TrCP- and Hrd1dependent degradation mechanisms. Mol. cell. biol. 31(22): 4500-4512.

Vadlapatla, R. K., Vadlapudi, A. D. and Mitra, A. K. (2013). Hypoxia-inducible factor-1 (HIF-1): a potential target for intervention in ocular neovascular diseases. Curr. drug targets. 14(8): 919-935.

Vander Heiden, M. G., Cantley, L. C., Thompson, C. B. (2009). Understanding the Warburg effect: the metabolic requirements of cell proliferation. Sci. 324: 1029-1033.

Vangala, J. R., Sotzny, F., Krüger, E., Deshaies, R. J., and Radhakrishnan, S. K. (2016). Nrf1 can be processed and activated in a proteasome-independent manner. Curr. biol. 26(18): R834R835.

Wang, W. and Chan, J. Y. (2006). Nrf1 is targeted to the endoplasmic reticulum membrane by an N-terminal transmembrane domain Inhibition of nuclear translocation and transacting function. J. Biol. Chem. 281: 19676-19687.

Wang, W. and Chan, J.Y. (2006). Nrf1 is targeted to the endoplasmic reticulum membrane by an N-terminal transmembrane domain: inhibition of nuclear translocation and transacting function. J. Biol. Chem. 281: 19676-19687.

Wang, W., Kwok, A. M. and Chan, J. Y. (2007). The p65 isoform of Nrf1 is a dominant negative inhibitor of ARE-mediated transcription. J. Biol. Chem. 282: 24670-24678. 
Waypa, G. B., Marks, J. D., Guzy, R., Mungai, P. T., Schriewer, J., Fokic, D. and Schumacker, P. T. (2010). Hypoxia triggers subcellular compartmental redox signaling in vascular smooth muscle cells. Circ Res. 106(3): 526-535.

Weidemann, A., Johnson, R. S. (2008). Biology of HIF-1alpha. Cell Death and Differ. 15: 621627.

Xu, Z., Chen, L., Leung, L., Yen, T. S., Lee, C. and Chan J. Y. (2005). Liver-specific inactivation of the Nrfl gene in adult mouse leads to nonalcoholic steatohepatitis and hepatic neoplasia. Proc. Natl. Acad. Sci. 102: 4120-4125.

Zhang Y., Crouch D. H., Yamamoto M., and Hayes J. D. (2006). Negative regulation of the Nrf1 transcription factor by its N-terminal domain is independent of Keap1: Nrf1, but not Nrf2, is targeted to the endoplasmic reticulum. The Biochem. J. 399(3): 373-385.

Zhang Y., Lucocq J. M., Yamamoto M. and Hayes J. D. (2007). The NHB1 (N-terminal homology box1) sequence intranscription factor $\mathrm{Nrfl}$ is required to anchor it to the endoplasmic reticulum and also to enable its asparagine-glycosylation. Biochem. J. 408: 161-172. 


\section{APPENDIX}

Mass spectrometry analysis raw data including the complete list of protein identified in each of five samples. 


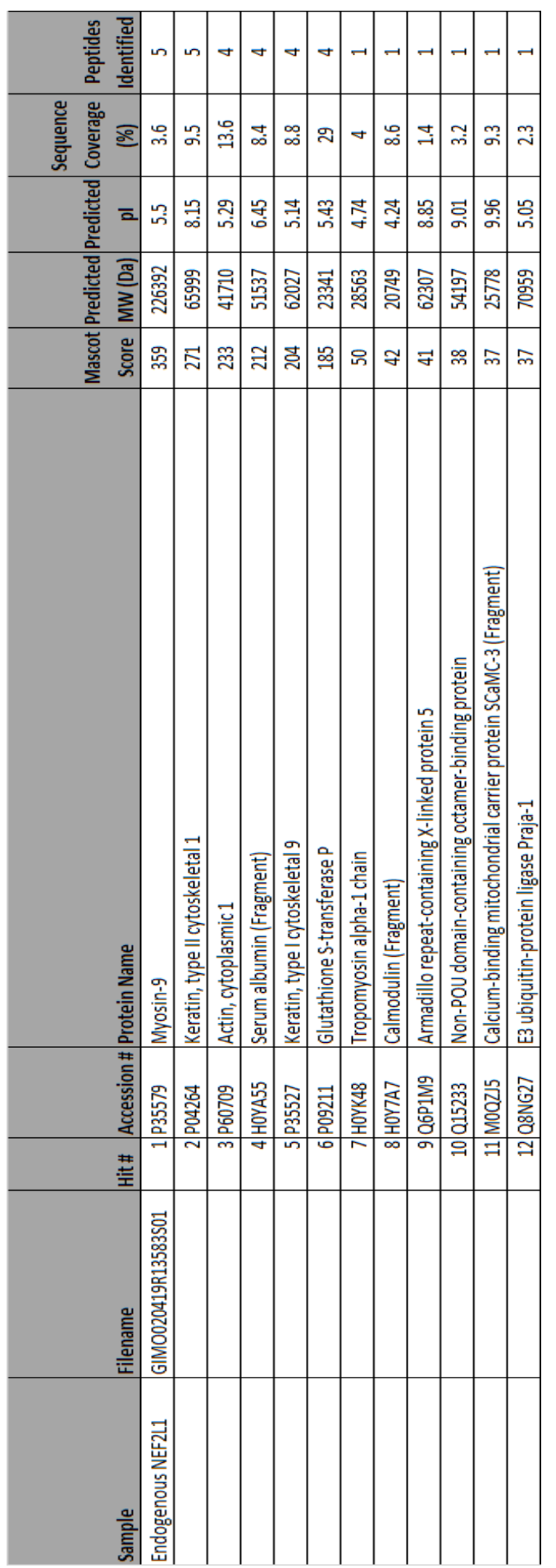




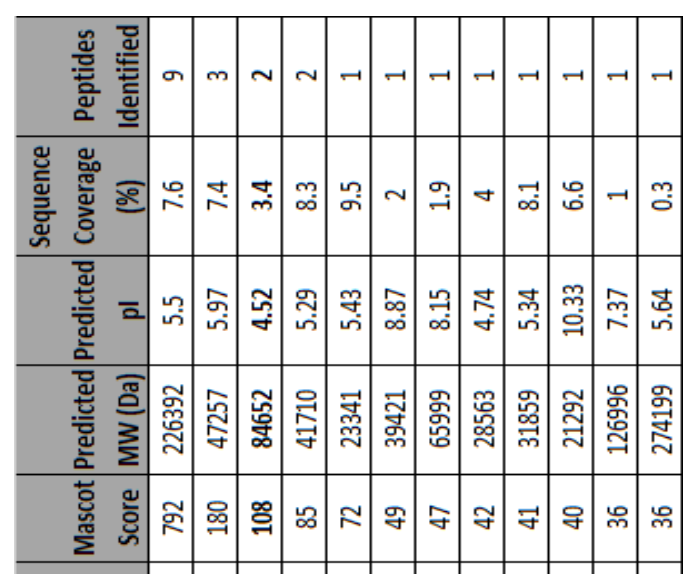

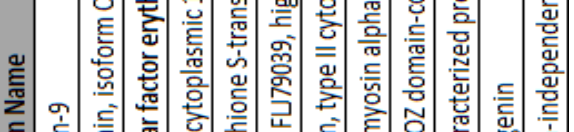

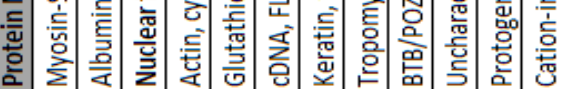

\#

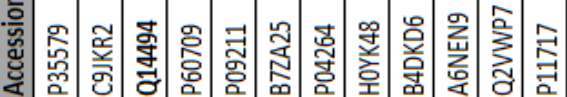

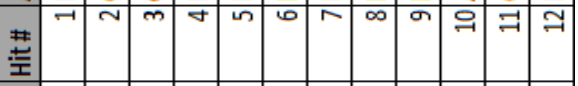

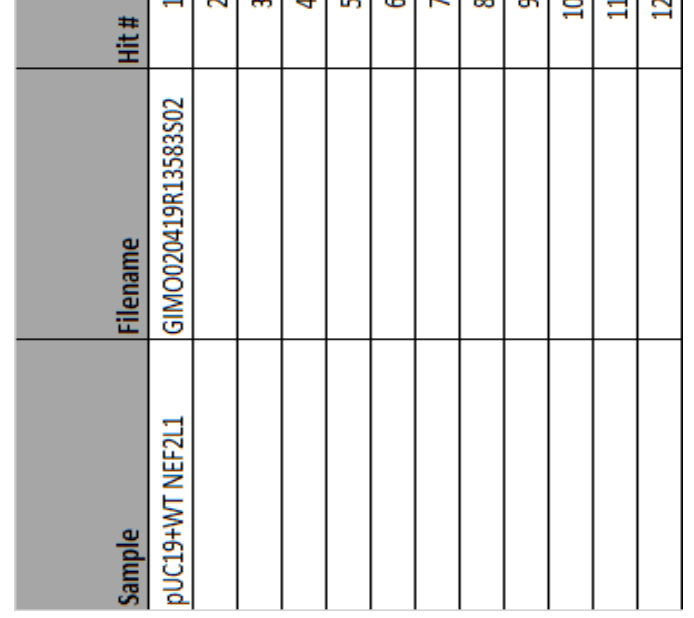




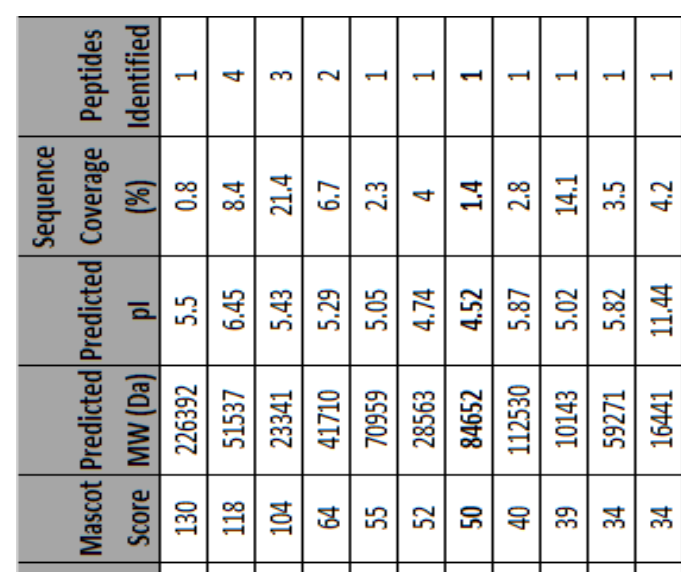

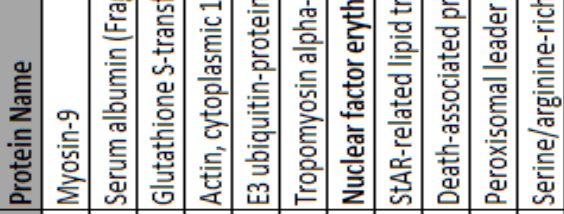

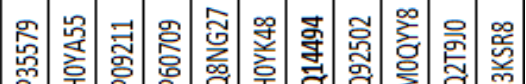

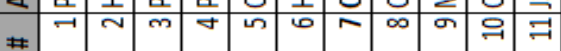

촐

商

II 


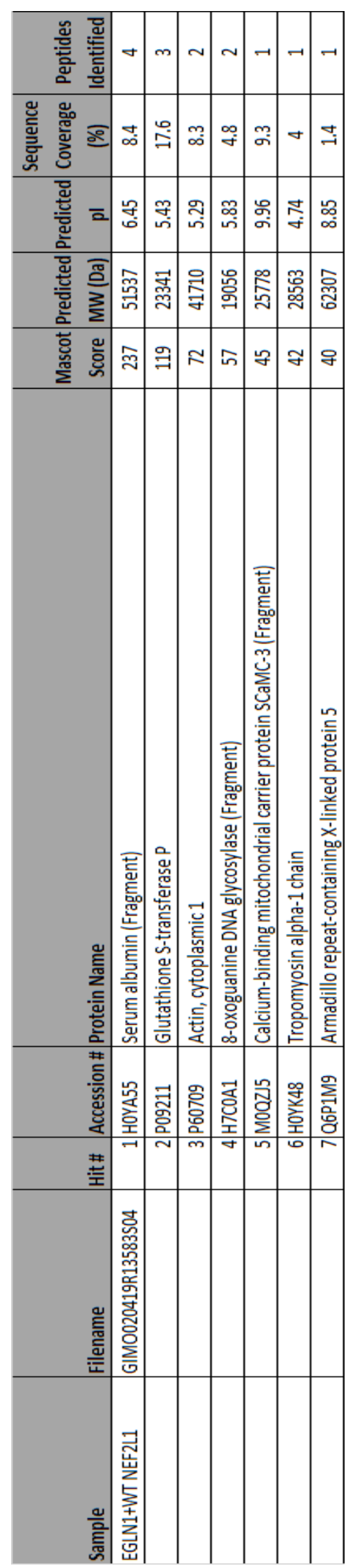




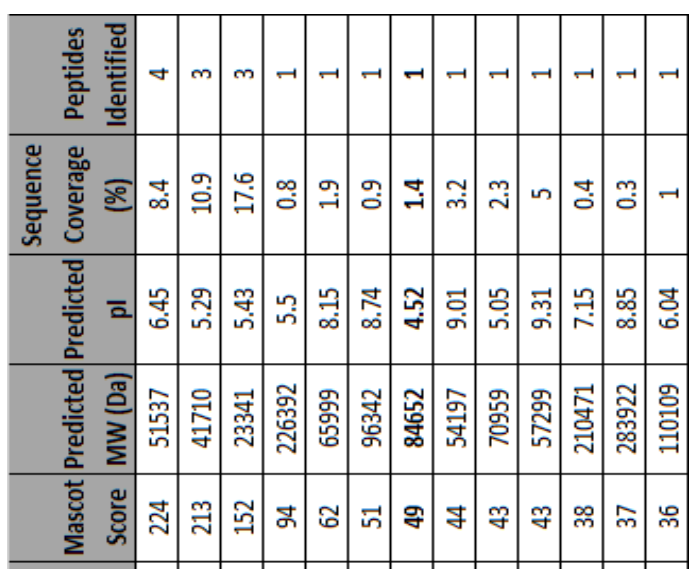

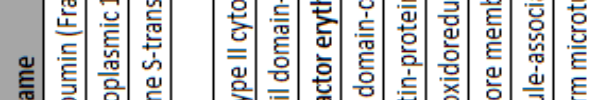

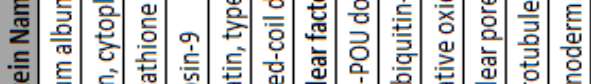

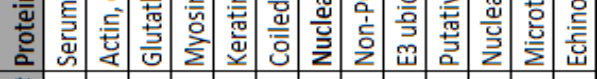

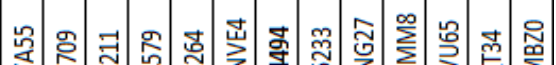

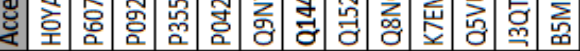

黄

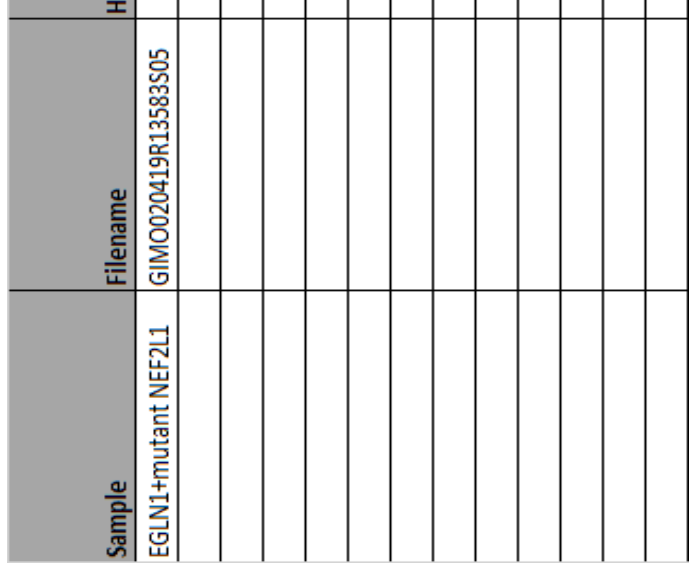

